The Role of Wintertime Radiation in Maintaining and Destroying Stable Layers

\author{
by \\ Matthew H. Savoie \\ Thomas B. McKee
}

Department of Atmospheric Science

Colorado State University

Fort Collins, Colorado

\title{
Department of Atmospheric Science
}





\title{
THE ROLE OF WINTERTIME RADIATION IN MAINTAINING AND DESTROYING STABLE LAYERS
}

\author{
Matthew H. Savoie \\ Thomas B. McKee
}

\begin{abstract}
This research was supported by
NOAA Cooperative Agreement \#NA 90-RAH00077 and National Science Foundation Grant \#ATM-9113898.
\end{abstract}
Atmospheric Science Department
Colorado State University
Fort Collins, Colorado
80523

July 1993

Atmospheric Science Paper No. 536 



\title{
THE ROLE OF WINTERTIME RADIATION IN MAINTAINING
}

\section{AND DESTROYING STABLE LAYERS}

\begin{abstract}
Surface measurements of the upwelling and downwelling, longwave and shortwave fluxes were made at two sites in western Colorado during January and February 1992, to determine the radiative effects on maintaining or destroying stable layers.

During the day, the surface received a net gain of energy, while at night there was a net loss. Over snow, the 24 hour surface energy gain was positive or negative and close to zero. A darker surface, soil, caused the energy gain to be positive and just slightly larger than zero. There is little difference in the energy balance between clear and cloudy days. The reduction of the incident solar flux due to clouds is compensated by the hindering of the longwave cooling, making each smaller, yet retaining a similar net irradiance.

Partitioning the energy into latent and sensible portions, the available daytime sensible heat flux useable for destroying boundary layers is small for these low solar angles of the winter season. The daytime sensible heat flux available is only 0.3 to $1.2 \mathrm{MJ} / \mathrm{m}^{2}$ over a snow surface and 1.4 to $2.3 \mathrm{MJ} / \mathrm{m}^{2}$ over soil when a Bowen ratio of 0.5 is assumed. This heat flux will not build a deep enough boundary layer to reconnect the surface air with the free atmosphere above. Examination of the Grand Junction 00 UTC soundings show that the depth of the
\end{abstract}


boundary layer during the beginning of the experiment to be less than $500 \mathrm{~m}$, not deep enough to reconnect the surface air with the air aloft, consistent with the sensible heat calculations. At the very end of the experiment, after DOY 40, less stable morning soundings with lower surface albedo allow for larger boundary layers to be built, but still usually less than $700 \mathrm{~m}$.

Over a 24 hour period, the sensible heat flux is negative or very small. The effects of clouds become apparent as well, with the reduced solar input and smaller longwave cooling during the night, resulting in the clear days losing more sensible heat than the cloudy days.

The cumulative effects of the average surface fluxes shows that during the first portion of the experiment Grand Junction CO, had a net loss of energy at the surface, when the snow disappears, the energy gain shifts signs and becomes larger and positive. Meeker $\mathrm{CO}$, on the other hand, does have a positive energy gain for a portion of the experiment, but the cumulative energy remains negative throughout the entire period. The average 24 hour sensible heat fluxes are negative at both sites, when abundant moisture exists at the surface, Bowen ratio of 0.5 . Only after melting and drying of the surface does a net gain of sensible energy allow the atmosphere to become heated from the surface for 24 hour periods.

Two models, a broadband infrared and a two stream shortwave model are used to determine the fluxes at the surface and top of the atmosphere. These values are compared with the observations from the experiment's surface station 
as well as historical ERBE data from space. The results show that quantitative values of the shortwave and longwave fluxes can be determined from NWS airsonde soundings in conjunction with these models. 


\section{Acknowledgments}

The authors would like to thank Dr. David Krueger and Dr. Thomas Vonder Haar for their helpful comments on this paper.

A special thanks also goes to the members of the research group. Odie Bliss for her valuable help in putting the final draft into a presentable form. John Kleist provided endless help with computer-related questions. Georg Mayr for his help understanding of the blocking process as well as for the less glamorous job of helping with the data recovery from the Meeker ground station.

Steve Cox and Paul Stackhouse are thanked for the use of their respective models as well as for the informative discussions on how to use the models.

Chris Cornwall, John Davis and Dave Wood are all thanked for their help in acquiring, understanding, and calibrating, the radiometers as well as the rest of the ground station instruments. Dr. "Rocky" Renquist is also thanked for allowing and watching the Grand Junction station. Judy Sorbie-Dunn is thanked for her help in drafting the final figures of the paper.

This work was supported under NOAA Cooperative Agreement \#NA 90-RAH00077 and NSF grant \#ATM-9113898. 
1. Introduction $\ldots \ldots \ldots \ldots \ldots \ldots \ldots \ldots \ldots \ldots \ldots \ldots \ldots \ldots \ldots \ldots \ldots \ldots$

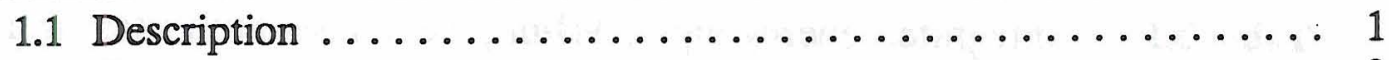

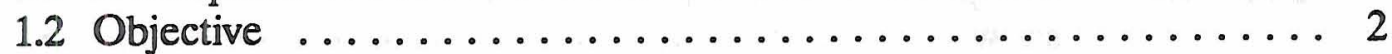

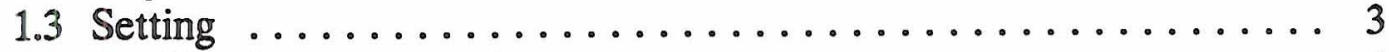

1.4 Justification $\ldots \ldots \ldots \ldots \ldots \ldots \ldots \ldots \ldots \ldots \ldots \ldots \ldots$

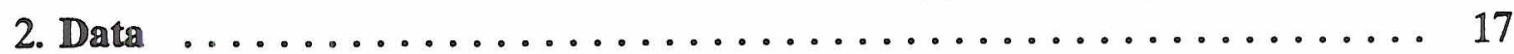

2.1 Ground Based ........................... 17

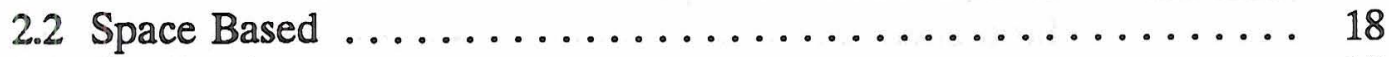

2.3 Quality Assurance .................. 18

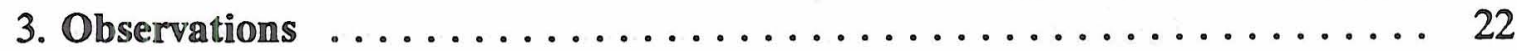

3.1 Radiation Diurnal Cycle ................... 22

3.2 Integrated Daily Fluxes . . . . . . . . . . . . . . 27

3.3 Surface Moisture Effects .................. 34

3.4 Cumulative Integrated Fluxes $\ldots \ldots \ldots \ldots \ldots \ldots \ldots \ldots$

4. Modelling Studies ......................... 49

4.1 Broadband Infrared flux model ............... 49

4.1.1 Downwelling Comparison .............. 50

4.1.2 Upwelling Comparison ................ 54

4.2 Two Stream Shortwave Model .................. 57

4.2.1 Downwelling Comparison ............... 57

4.2.2 Upwelling Comparison ................ 62

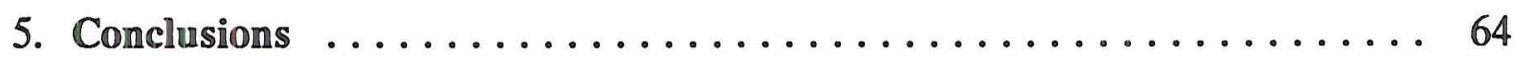

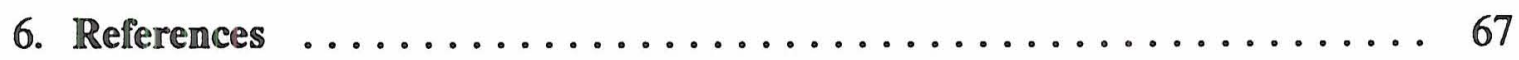




\section{List of Tables}

Table 1.1 Integrated energy required to build boundary layer . . . . . . . 14

Table 3.1 Integrated energy input, $\mathrm{MJ} / \mathrm{m}^{2}$; clear skies both sites over snow ............................... 29

Table 3.2 Integrated energy input, $\mathrm{MJ} / \mathrm{m}^{2}$; clear skies soil at Grand Junction ............................. 30

Table 3.3 Integrated energy input, $\mathrm{MJ} / \mathrm{m}^{2}$; cloudy skies snowcover at both sites .......................... 31

Table 3.4 Integrated energy input, $\mathrm{MJ} / \mathrm{m}^{2}$; cloudy skies soil at Grand

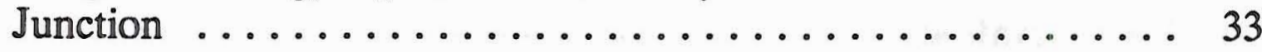

Table 3.5 Sensible Heat Flux assuming Bowen ratio of $0.15 \ldots \ldots \ldots$

Table 3.6 Sensible Heat Flux assuming Bowen ratio of $0.5 \ldots \ldots . \ldots$

Table 3.7 Average Net Heat Flux by surface and sky type ........ 38 


\section{List of Figures}

Figure 1.1 Idealized soundings used in boundary layer model. $\ldots \ldots \ldots 6$

Figure 1.2 Theoretical maximum height of boundary layer versus day of year for changes in latitude. Lapse rate is $3.5 \mathrm{~K} / \mathrm{km}$. Albedo is $25 \%$. Bowen ratio is $0.5 \ldots \ldots \ldots \ldots \ldots \ldots \ldots$

Figure 1.3 Theoretical maximum height of boundary layer versus day of year for differing lapse rates. Latitude is $40^{\circ} \mathrm{N}$. Albedo is $25 \%$. Bowen ratio is $0.5 . \ldots \ldots \ldots \ldots \ldots \ldots \ldots \ldots$

Figure 1.4 Theoretical maximum boundary layer height versus sensible energy input for differing stabilities. . . . . . . . . 13

Figure 1.5 Theoretical maximum boundary layer height versus day of year for varying Bowen ratios. Lapse rate is $3.5 \mathrm{~K} / \mathrm{km}$. Albedo is $25 \%$. Latitude is $40^{\circ} \mathrm{N}$. . . . . . . . . . . 15

Figure 3.1 Diurnal cycle of shortwave fluxes from Grand Junction. . . . . 23

Figure 3.2 Diurnal cycle of longwave fluxes from Grand Junction. . . . . 25

Figure 3.3 Net integrated 24 hour flux versus day of year for Meeker and Grand Junction. ................. 40

Figure 3.4 Cumulative net energy calculated every ten minutes versus day of year for Meeker and Grand Junction. .......... 42

Figure 3.5 Cumulative daily shortwave radiation versus day of year for Meeker and Grand Junction. . . . . . . . . . . . . . 43

Figure 3.6 Cumulative daily sensible heat flux versus day of year at Grand Junction for various Bowen ratios. . . . . . . . . . 44

Figure 3.7 Cumulative daily sensible heat flux versus day of year at Meeker for various Bowen ratios. ............ 45

Figure 3.8 Depth of boundary layer from the 00 UTC Grand Junction sounding versus Day of Year................ 47

Figure 4.1 Broadband model calculated longwave downwelling surface flux versus the instrument observed flux for clear days ..... 51 
Figure 4.2 Broadband model calculated longwave downwelling surface flux versus the instrument observed flux for cloudy days ..... 53

Figure 4.3 Broadband model calculated longwave upwelling top of atmosphere flux versus the ERBE measured flux.

Calculations with afternoon soundings are represented with an "x"; morning soundings with a "+"............ 56

Figure 4.4 Broadband model calculated longwave upwelling top of atmosphere flux versus the ERBE measured flux. The calculated values are the result of averaging the model results for the morning and afternoon soundings. .......... 58

Figure 4.5 Two stream model calculation of surface downwelling shortwave flux versus the instrument observed flux. Model used the instrument observed surface albedo.......... 60

Figure 4.6 Two stream model calculation of surface downwelling shortwave flux versus the instrument observed flux. Model used prescribed $30 \%$ albedo. . . . . . . . . . . . . 61 


\section{Introduction}

\subsection{Description}

Stable layers in the lowest portion of the atmosphere are often found in the Great Basin of the western United States during the winter months. Strong stable layers, where the temperature profile is increasing or nearly constant with height, can act to decrease air quality, as a stable layer inhibits momentum exchange between air near the surface and the air aloft, causing air stagnation and inadequate ventilation of locally generated pollution (Wolyn 1989). In addition to the stability reducing turbulent mixing, orographic blocking occurs along the Colorado western slope. A mesoscale high forms atop the barrier and the resulting pressure gradient causes low level air impinging the mountains to be slowed and deflected, rather than rising up and over the barrier (Mayr 1993). These decoupled periods lead to difficulties in forecasting daily maximum and minimum temperatures as the normally indicative $700 \mathrm{hPa}$ temperatures can change as much as $15^{\circ}$ to $20^{\circ} \mathrm{C}$ per day while the surface may only warm $6^{\circ}$ to $8^{\circ} \mathrm{C}$ (Wolyn 1989).

This experiment was conducted to determine the role of radiation in maintaining and destroying wintertime stable layers. To accomplish this, the project had the opportunity to collect a unique data set. In addition to a standard meteorological ground station, a continuous set of surface based radiation data 
was collected at two separate locations on the Western Slope of the Rocky Mountains over changing surface conditions.

\subsection{Objective}

Through the use of the ground based data in conjunction with vertical profiles, this project will show quantitatively in which regimes stable layers are maintained along the western slope. Wintertime low solar angles and abundant surface moisture reduce the energy incident at the surface. Often, during the winter period the diurnal cycle of radiation is such that the boundary layer does not grow to a height sufficient to recouple the surface to the free atmosphere above (Wolyn 1989). In a closed system, a basin or non draining valley for example, consecutive days with a total energy loss over a 24 hour period would result in consecutively lower surface temperatures each day. Unfortunately, in a valley regime or a system that is not closed, advection can dominate and this effect may not be identified (Whiteman 1992).

Surface based radiation measurements will determine the integrated energy input to the system. The effects of clouds and surface albedo will be studied. Latent heating will be considered, and the daytime and nighttime periods will be examined separately. This cumulative data will be used to examine the energy balance at the surface; whether it is positive, negative or close to zero.

Additionally, radiative transfer models will be used with NWS soundings and compared to the observations at the surface stations to confirm the models' 
ability to accurately reproduce the radiative properties of a given atmosphere for both the surface and top of the atmosphere. Verification of the models will allow for the generalization of the results to other temperature and humidity profiles. Knowledge of these surface values from models would be useful in determining whether a given day would tend to support or destroy a stable layer, helping the $\max / \min$ temperature and air quality (burning ban) forecasts.

\subsection{Setting}

Surface stations were situated in Meeker and Grand Junction CO. Both are located on the western slope of the Rocky Mountains, where stable atmospheric conditions are often found during the winter period. Both stations collected data from DOY 10 to DOY 57 (January 10 to Feb 26), 1992.

Located at $40^{\circ} 17^{\circ} \mathrm{N} \times 107^{\circ} 51^{\circ} \mathrm{W}$ and elevation $1989 \mathrm{~m}$, the Meeker station is set in the White River Valley, on the grounds of the Upper Colorado Plant Center. The Valley is oriented East-West. It is $38 \mathrm{~km}$ long and $13 \mathrm{~km}$ wide. The site is on the south slope of the valley just southwest of where the White River meets the Little Beaver Creek. This is about one third of the way down the valley. Further along the valley the tributaries Flag Creek and Sheep Creek enter from the south, and Strawberry Creek from the North. This site was located over a field of short-clipped Russian rye. Snow covered the field for the entire experimental period, but occasionally the rye emerged from the snow, giving a slightly less than completely snow covered ground surface. 
Orchard Mesa was the location of the Grand Junction station. At $39^{\circ} 03^{\prime}$ $\mathrm{N} \times 108^{\circ} 27^{\circ} \mathrm{W}$ and elevation $1451 \mathrm{~m}$, it is located just East of the intersection of the Colorado and Gunnison Rivers. The two rivers join in a valley which is $16 \mathrm{~km}$ wide and runs Southeast to Northwest for $46 \mathrm{~km}$ before gradually turning to the Southwest. The Gunnison River flows in from the Southeast and the Colorado enters from a narrow canyon to the Northeast. The Book Cliffs form the Northeast wall of the valley while the other side is a more gentle rise to a similar elevation. This site was located in the middle of a tilled field and at the beginning of the experiment the site was snow covered, but during the experiment the snow melted and the end of the period the surface was the dark soil of the field.

\subsection{Justification}

Determining how surface radiative fluxes affects stable layers leads to an interesting experiment. There is a net flux of power, $\mathrm{F}_{\mathrm{N}}$, striking the earth at a given point. This net flux is broken down into shortwave and longwave components, $F_{S W}$ and $F_{L W}$ respectively. Each of these in turn is comprised of an upwelling and a downwelling portion, $\mathrm{F}_{\mathrm{XW} \uparrow}$ and $\mathrm{F}_{\mathrm{XW}}$, representing the energy reflected or emitted from the surface of the earth and the portion passing through or originating in the atmosphere.

The net flux, $F_{N}$, at the surface can go into several processes. The energy balance equation is, 


$$
F_{N}=H+L E+G
$$

The net flux, $F_{N}$, is divided among the sensible heat flux, $H$, the latent heat flux, $\mathrm{LE}$, and ground heat flux, G. A stable layer can be removed by a positive sensible heat flux from the surface to the atmosphere. Figure 1.1 shows the initial sounding in potential temperature coordinates. As energy is added to the system at the surface, in the form of an continuous sensible heat flux, the profile warms. Vertical mixing will make the sounding neutral (vertical). The depth of the mixed/neutral layer will be dependent on $Q_{H}$, the total energy added to the profile. This daytime sensible energy is given by,

$$
Q_{\mathrm{H}}=\int_{\text {sunise }}^{\text {sunset }} \mathrm{Hdt} \text {. }
$$

Starting with the First Law of Thermodynamics, an expression for the change in energy, $\Delta Q_{H}$, required to increase the potential temperature of a volume of air, $\mathrm{V}$, by an amount $\Delta \theta$ is,

$$
\Delta Q_{\mathrm{H}}=\rho V c_{\mathrm{p}} \frac{T}{\theta} \Delta \theta
$$

Where $\rho$ is the density of air, $c_{p}$ is the specific heat of air at constant pressure, $1000 \mathrm{~J} / \mathrm{kg} / \mathrm{K}, \mathrm{T}$ and $\theta$ are temperature and potential temperature. Put into integral form, the total energy required to build a mixed layer to a depth $Z_{\max }$ is, 

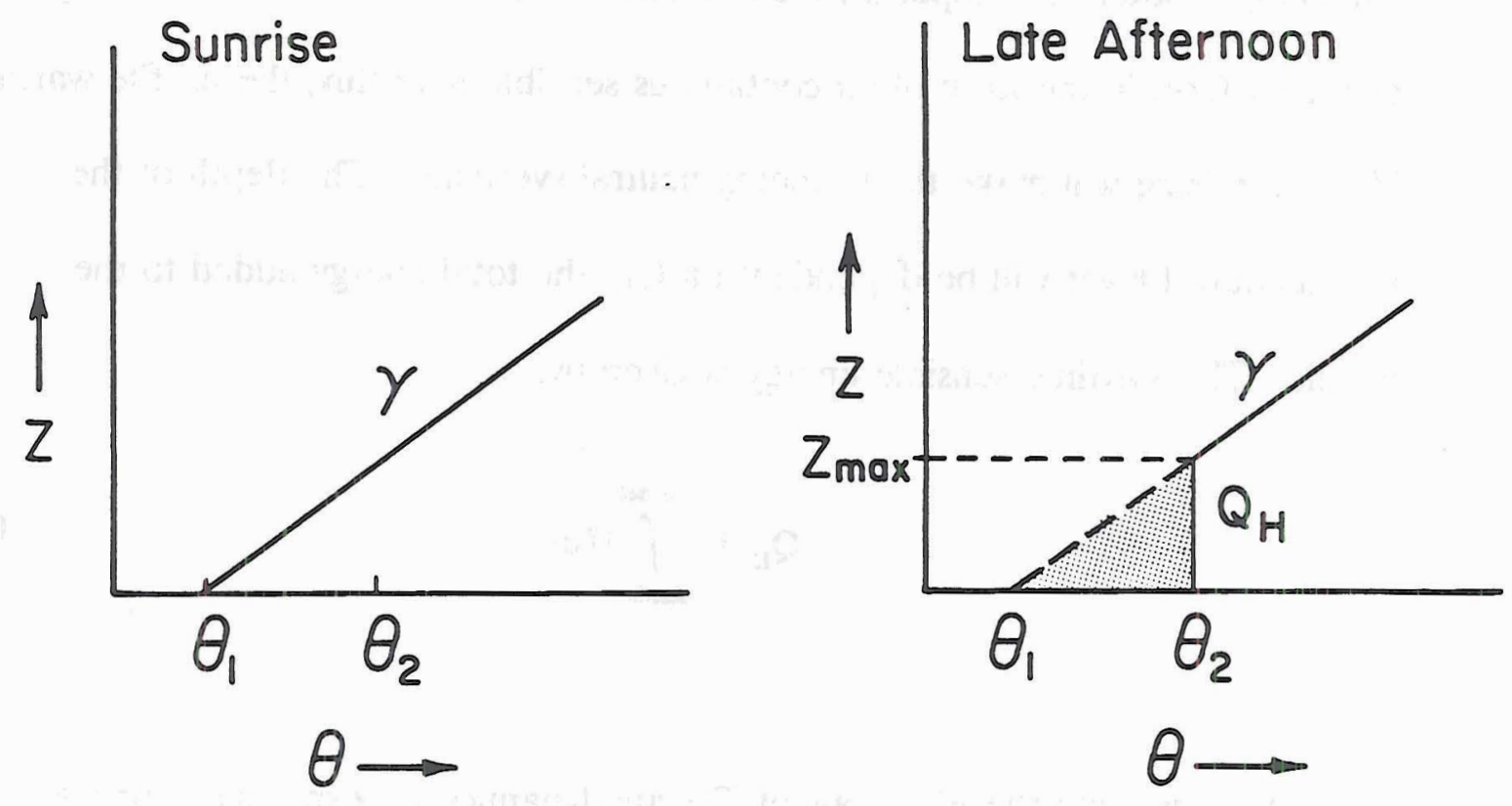

Figure 1.1 Idealized soundings used in boundary layer model. At sunrise, the sounding is stable with a constant potential temperature lapse rate of $\gamma$ and surface temperature $\theta_{1}$. In the late afternoon as the sensible heat flux changes over to negative, the sounding has been warmed to a depth $Z_{\max }$ and temperature $\theta_{2}$. The sensible energy, $\mathrm{Q}_{\mathrm{H}}$, required to warm this region is shaded. 


$$
Q_{\mathbb{H}}=\int_{0}^{Z_{\max }} \int_{0}^{1} \int_{0}^{1} \rho c_{p} \frac{T}{\theta} \Delta \theta d x d y d z
$$

Assume the atmosphere is stable with a constant potential temperature lapse rate of $\gamma$. Density is constant in the boundary layer, $\rho=0.93 \mathrm{~kg} / \mathrm{m}^{3}$. The quantity $\mathrm{T} / \theta$ is $(\mathrm{p} / 1013)^{\mathrm{R} / \mathrm{cp}} \approx 0.93$ for an elevation of $1.5 \mathrm{~km}$. Figure 1.1 shows for a constant lapse rate, the potential temperature increment is given as a function of elevation, $\mathrm{z}$ :

$$
\Delta \theta(z)=\gamma\left(Z_{\max }-z\right)
$$

Therefore, the total energy per unit area required to neutralize a stable layer over a horizontally homogenous plane is

$$
Q_{H}=\rho c_{p} \frac{T}{\theta} \int_{0}^{Z_{\max }} \gamma\left(Z_{\max }-z\right) d z .
$$

Integrating and rearranging, the maximum depth a boundary layer could achieve with a given $Q_{H}$ is,

$$
Z_{\max }=\sqrt{\frac{2 Q_{H}}{\rho c_{p} \gamma \frac{T}{\theta}}} .
$$

Examination of differing sensible heat input, $\mathbf{Q}_{H}$, gives insight to the problem of how to remove stable layers. The net flux, $\mathrm{F}_{\mathrm{N}}$, is determined by 
calculating the theoretical $\mathrm{F}_{\mathrm{SW}}$ from day of the year, latitude, and albedo, using a value of 80 percent transmission of the direct solar radiance for the $\mathrm{F}_{\mathrm{SW}_{b}}$; this value agrees well with this experiments observations. A standard atmosphere (McClatchey et. al. 1972) for both midlatitude summer and winter were used in a broadband radiative transfer model to get an average value of $F_{L W}$ at the surface for the daylight period. Integrating $\mathrm{F}_{\mathrm{N}}$ over the daylight hours gives the total energy gain at the surface, $Q_{N}$.

The Bowen ratio, $\beta$, is introduced to transform the net flux into sensible heat flux. It is the ratio of sensible heat flux to latent heat flux.

$$
\beta=\frac{H}{L E}
$$

Assuming the ground flux is negligible and combining the above with equation 1 , the sensible heat flux is,

$$
H=\frac{\beta}{\beta+1} \mathbb{F}_{N} \text {. }
$$

For the present example, the fraction of the net flux used for evaporation during the day is the important quantity. If an average Bowen ratio is assumed for a day, then the sensible energy is expressed by, 


$$
Q_{\mathrm{H}}=\frac{\beta}{\beta+1} Q_{\mathrm{N}} \text {. }
$$

A theoretical value of $Q_{N}$ can be determined for any day of the year, changes in latitude, and surface albedo. $\mathrm{Q}_{\mathrm{N}}$ with a given Bowen ratio and stability (potential temperature lapse rate) will allow for a calculation of the maximum height a neutral boundary layer could grow.

Typical wintertime boundary layers on the western slope of Colorado often reach only $500 \mathrm{~m}$ during the day. The Rocky Mountains to the East reach to about $1500 \mathrm{~m}$ above the Meeker site. During episodes of deep stable layers along the western slope, when the energy input is not great enough to mix the air up to the free atmosphere, often only half the barrier height, the air can remain trapped.

With this in mind, examine some of the effects. Figure 1.2 shows how the maximum height of the boundary layer changes with latitude. The atmosphere is assumed to have a constant potential temperature lapse rate of $\gamma=3.5 \mathrm{~K} / \mathrm{km}$. Moisture effects are parameterized by the Bowen ratio, in this case $\beta=0.5$. The albedo of the surface is $25 \%$. The first remarkable feature is the summer height of the theoretical boundary layer. It is nearly the same for each latitude. In summer, the higher latitudes getting extra hours of incident solar radiation making up for the indirect angle of the sun. The actual values of the height are probably not reasonable. A Bowen ratio of 0.5 may or may not be a logical estimate 


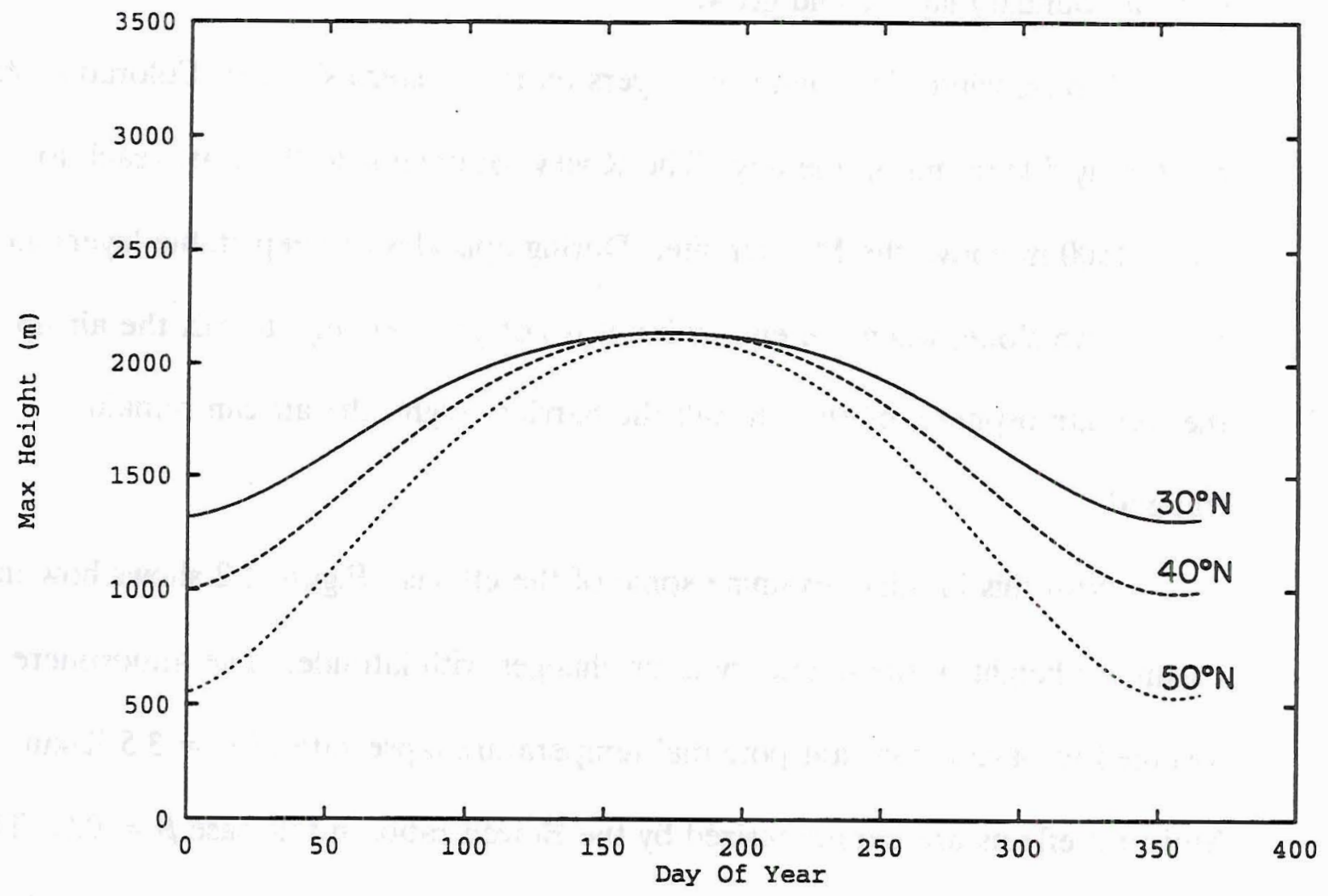

Figure 1.2 Theoretical maximum height of boundary layer versus day of year for changes in latitude. Lapse rate is $3.5 \mathrm{~K} / \mathrm{km}$. Albedo is $25 \%$. Bowen ratio is 0.5 . 
depending on the surface moisture availability. In contrast, the wintertime heights are very dependent on the latitude. At the highest latitude, $50^{\circ} \mathrm{N}$, the incident solar radiation is small, and hence there is little energy available to build a deep boundary layer. At the latitude of Grand Junction and Meeker Colorado, $40^{\circ} \mathrm{N}$, the wintertime boundary layers would develop to around $1000 \mathrm{~m}$; this is below the level of the mountain barrier.

The stability also plays a role in determining how deep a boundary layer can grow. Figure 1.3 shows max heights for differing lapse rates. The latitude corresponds to that of the experimental sites, $40^{\circ} \mathrm{N}$. Bowen ratio and surface albedo are 0.5 and 0.25 respectively. Here the summer PBL is affected most by the increase in stability. The winter PBLs are less affected because of the square root dependence of the height. This shows that during the winter months, boundary layers at this latitude will have trouble building to a significant depth. Figure 1.4 shows another view of stability effects of PBL depth. This shows the square root dependence of depth to energy input (EQ. 7), and the differences for changing lapse rates. It is interesting that the energy required to build a small boundary layer is very similar for all four stabilities. This shows that very little energy is needed to build a small boundary layers due to the square root dependence of energy to height. This effect is quickly squelched as the more stable atmospheres require much more energy to build PBLs to comparable depths as the less stable counterparts. This is shown numerically in table 1.1. It only takes $0.7 \mathrm{MJ} / \mathrm{m}^{2}$ of energy more to build a $500 \mathrm{~m}$ neutral layer from an 


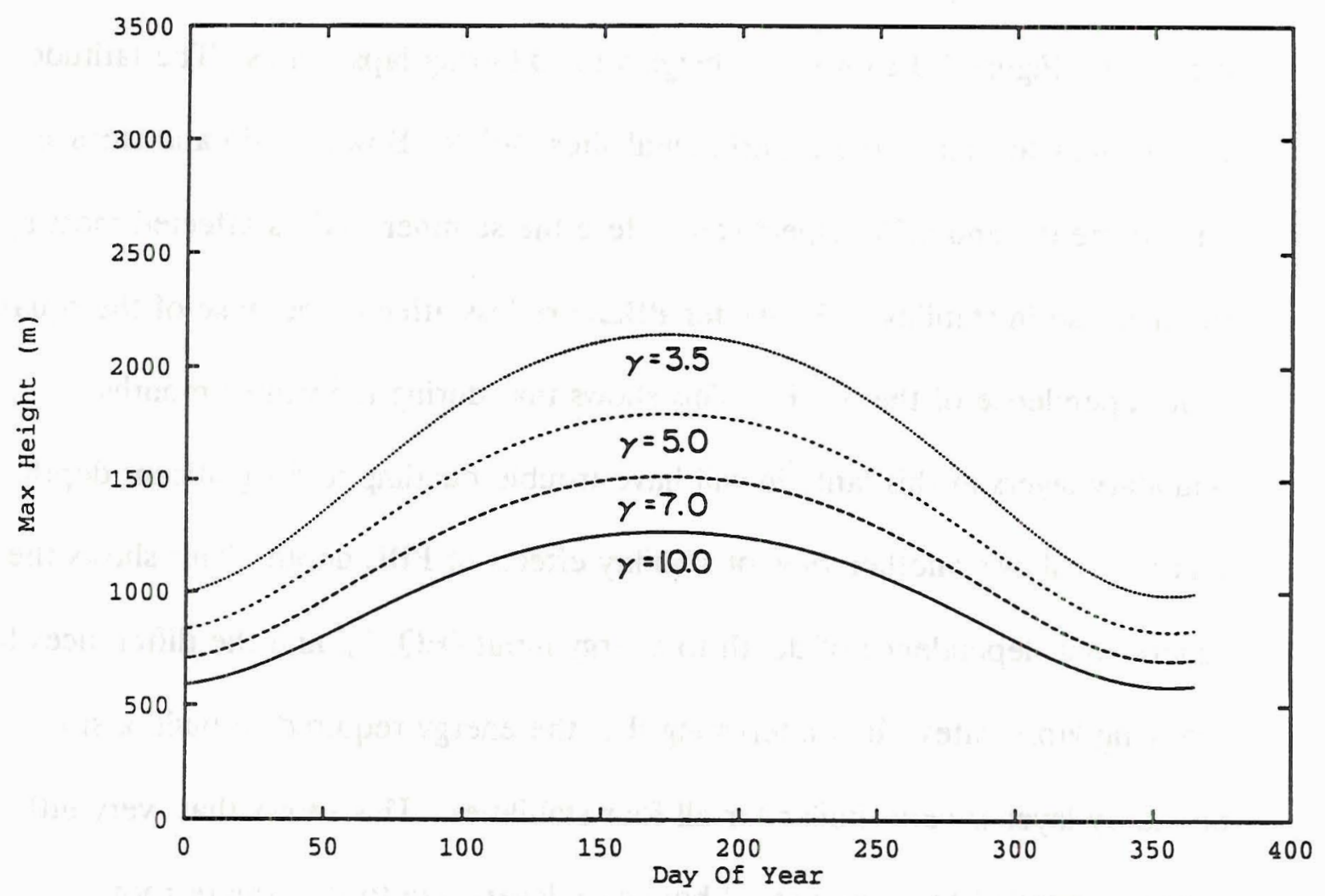

Figure 1.3 Theoretical maximum height of boundary layer versus day of year for differing lapse rates. Latitude is $40^{\circ} \mathrm{N}$. Albedo is $25 \%$. Bowen ratio is 0.5 . 


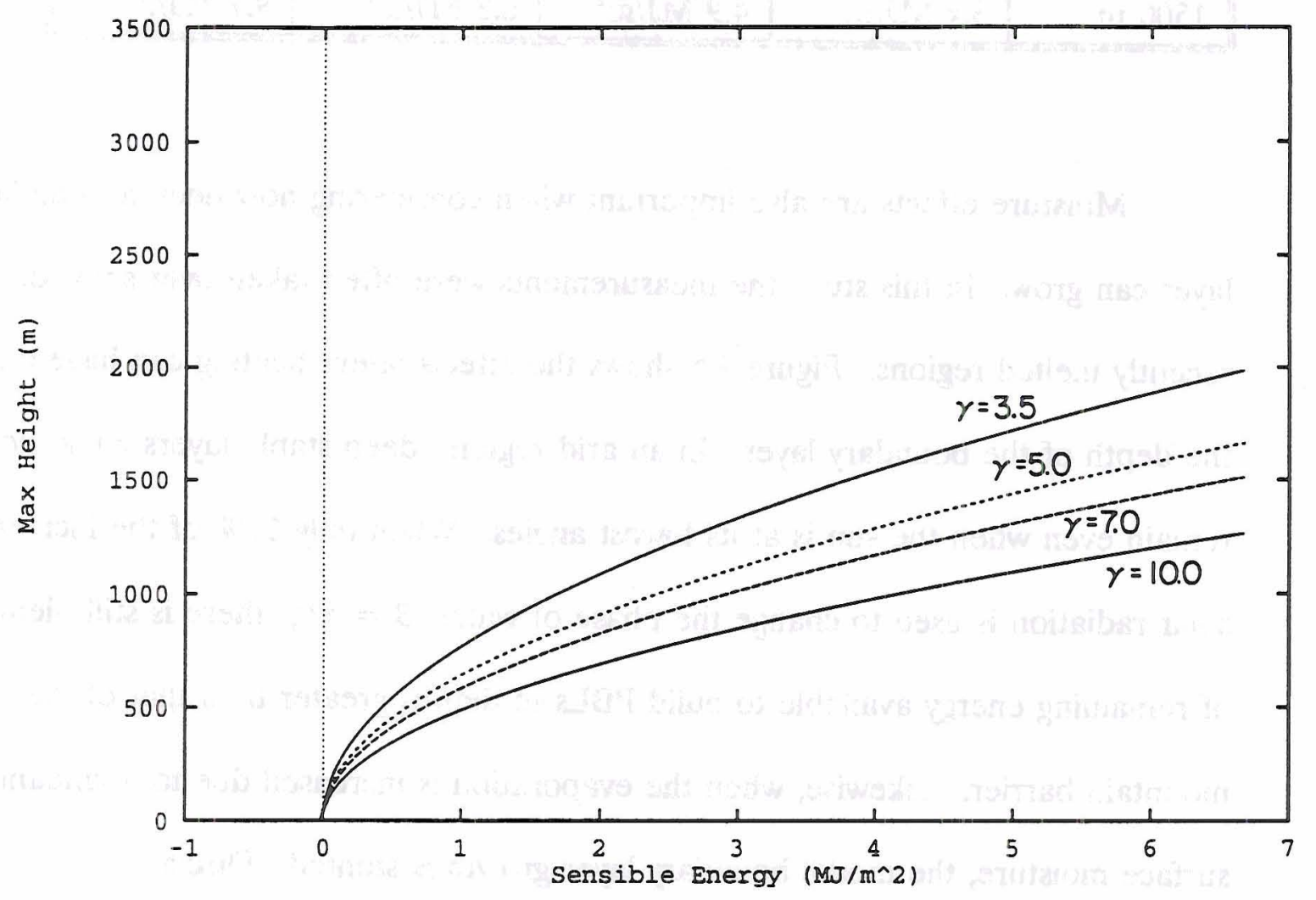

Figure 1.4 Theoretical maximum boundary layer height versus sensible energy input for differing stabilities. 
original sounding of $10 \mathrm{~K} / \mathrm{km}$ as compared to $3.5 \mathrm{~K} / \mathrm{km}$. But comparing a $1000 \mathrm{~m}$ layer, the energy difference is over $2.8 \mathrm{MJ} / \mathrm{m}^{2}$.

Table 1.1 Integrated energy required to build boundary layer

\begin{tabular}{|l|l|l|l|l||}
\hline \hline Lapse Rate & $3.5 \mathrm{~K} / \mathrm{km}$ & $5.0 \mathrm{~K} / \mathrm{km}$ & $7.0 \mathrm{~K} / \mathrm{km}$ & $10.0 \mathrm{~K} / \mathrm{km}$ \\
\hline \hline \multicolumn{5}{|||}{ Energy Required to Build Neutral Boundary Layer } \\
\hline $500 \mathrm{~m}$ & $0.38 \mathrm{MJ} / \mathrm{m}^{2}$ & $0.54 \mathrm{MJ} / \mathrm{m}^{2}$ & $0.76 \mathrm{MJ} / \mathrm{m}^{2}$ & $1.08 \mathrm{MJ} / \mathrm{m}^{2}$ \\
\hline $1000 \mathrm{~m}$ & $1.5 \mathrm{MJ} / \mathrm{m}^{2}$ & $2.2 \mathrm{MJ} / \mathrm{m}^{2}$ & $3.0 \mathrm{MJ} / \mathrm{m}^{2}$ & $4.3 \mathrm{MJ} / \mathrm{m}^{2}$ \\
\hline $1500 \mathrm{~m}$ & $3.4 \mathrm{MJ} / \mathrm{m}^{2}$ & $4.9 \mathrm{MJ} / \mathrm{m}^{2}$ & $6.8 \mathrm{MJ} / \mathrm{m}^{2}$ & $9.7 \mathrm{MJ} / \mathrm{m}^{2}$ \\
\hline
\end{tabular}

Moisture effects are also important when considering how deep a boundary layer can grow. In this study the measurements were often taken over snow or recently melted regions. Figure 1.5 shows the effects latent heating can have on the depth of the boundary layer. In an arid region, deep stable layers could not remain even when the sun is at its lowest angles. When only $17 \%$ of the incident solar radiation is used to change the phase of water, $\beta=5.0$, there is still plenty of remaining energy available to build PBLs to depths greater than that of the mountain barrier. Likewise, when the evaporation is increased due to abundant surface moisture, the model boundary layer growth is stunted. Direct measurements of the energy budget components were not made; therefore, some assumptions are made about the Bowen ratio at the experimental sites.

Theory shows, shallow boundary layers can form readily with small amounts of energy, but to build deeper boundary layers, the lapse rate plays an increasingly important role. On the western slope, stable layers of $10 \mathrm{~K} / \mathrm{km}$ are 


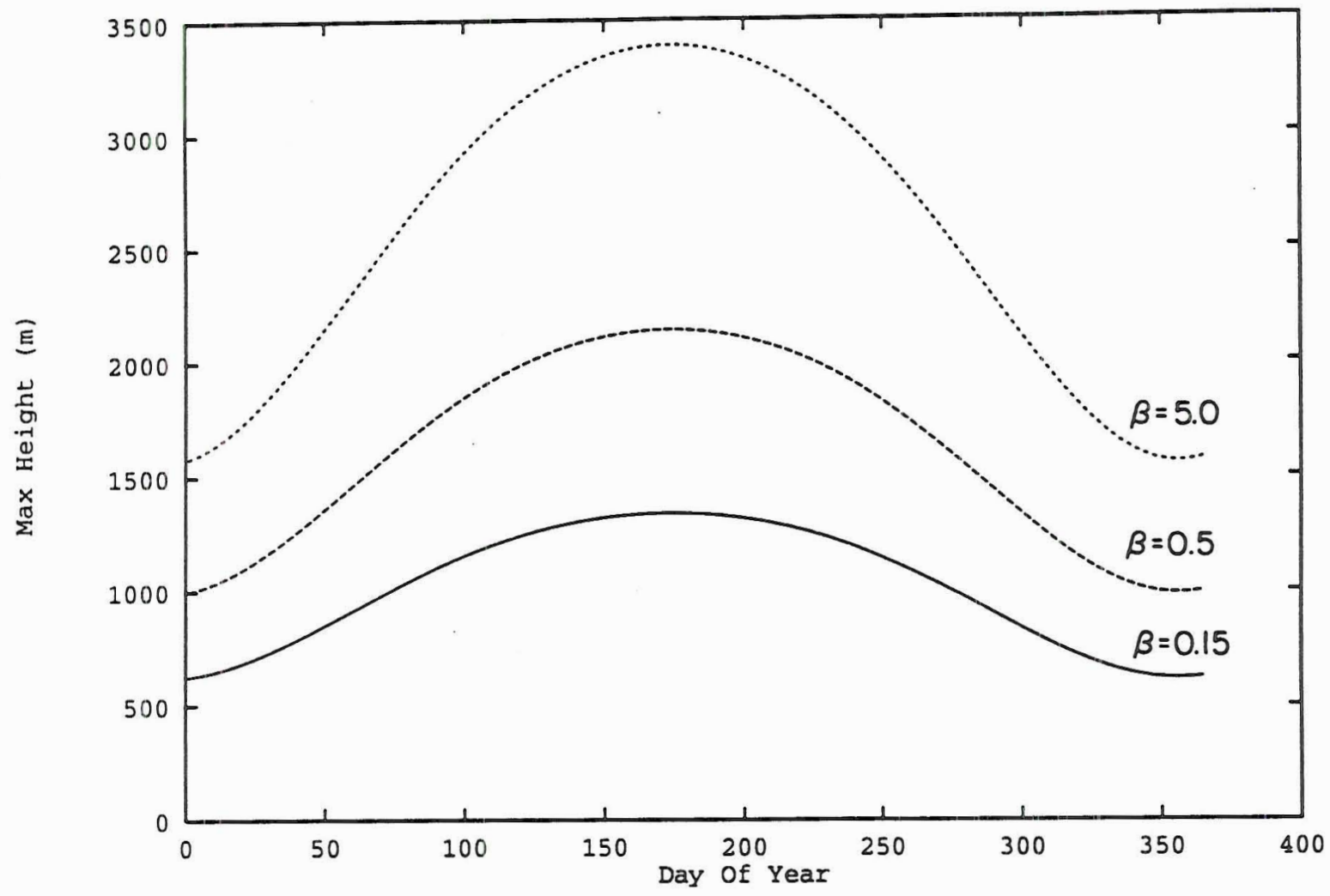

Figure 1.5 Theoretical maximum boundary layer height versus day of year for varying Bowen ratios. Lapse rate is $3.5 \mathrm{~K} / \mathrm{km}$. Albedo is $25 \%$. Latitude is $40^{\circ} \mathrm{N}$. 
often found to depths of 1500 meters. This knowledge and the results of the energy study clearly show that during winter at $40^{\circ} \mathrm{N}$ there is a good possibility that PBLs will not grow to a depth great enough to recouple the lower atmosphere with the free atmosphere above. 


\section{Data}

\subsection{Ground Based}

On the ground, standard surface meteorological stations were set up on h-frames at each site. Wind direction and speed were measured with a R.M. Young Model 05103 Wind Monitor. A thermistor measured temperature and relative humidity was measured with a carbon type hygristor. A chronological series of meteorological variables was accumulated at 10 minute intervals with the Campbell Scientific 21x Data Logger. Instantaneous values were collected for, temperature, humidity, wind direction, and wind speed. Ten minute averages were taken of the radiative fluxes.

Each station also included a two pair of horizontally mounted radiometers to measure the upwelling and downwelling radiation. $F_{\mathrm{SW}_{\uparrow}}$ and $\mathrm{F}_{\mathrm{SW} \downarrow}$ were measured with an Eppley Precision Spectral Pyranometers (PSP). PSPs measure the hemispheric, shortwave flux in the spectral range of 0.285 to $2.8 \mu \mathrm{m}$. The longwave fluxes were measured by Eppley Precision Infrared Radiometers (PIRs), or pyrgeometers. The dome of the PIR is vacuum coated with a interference filter eliminate the shortwave fluxes during the daylight hours. This coating effectively eliminates the transmission of flux into the instrument of wavelengths less than $4 \mu \mathrm{m}$; meanwhile, the dome reflects wavelengths longer than $50 \mu \mathrm{m}$.

In addition to the meteorological stations, atmospheric soundings were used for initializing radiative models as well as determining the depth of the strong 
stable layers. Often, the 00 and 12 UTC soundings from the National Weather Service station at Grand Junction were used to represent the atmospheric conditions at both stations.

\subsection{Space Based}

Comparison of the surface data with the model results was accomplished given the data collected and the soundings provided. Could the surface radiation budget at the surface be determined from space? To answer this question, historic ERBE data was retrieved. Confidence in the radiative codes and a relatively good agreement between the top of the atmosphere observed and model calculated would allow us to acquire accurate surface fluxes. The product received from the ERBE satellite are the average daily upwelling fluxes at the top of the atmosphere. The scanned data is gridded into $2.5^{\circ} \times 2.5^{\circ}$ boxes and the final product is the average of all of the satellite observations for the given day. Longwave, shortwave, and net fluxes are all available. December 1986 and January 1987 data were collected, hoping for conditions similar to the experimental period.

\subsection{Quality Assurance}

Errors are an important consideration when measuring radiative quantities. Uncertainties cannot be removed; but, with careful calibration the instrument can 
measure more accurately. This is true for radiometers. The error in the recorded radiation can be lowered with careful calibration.

The PSPs arrive calibrated by Eppley, but since the response of the instruments change with time, they are calibrated against other Eppley units that have themselves been calibrated against standards at NOAA in Boulder, CO. The declared accuracy of these instruments is about $1 \%$, but at low solar angles this is probably optimistic. Duda et al. (1991), have given an accuracy of these instruments to be $5 \mathrm{~W} / \mathrm{m}^{2}$. Daytime maximums of 600 to $750 \mathrm{~W} / \mathrm{m}^{2}$ reported in this study are such that $1 \%$ of them is near $5 \mathrm{~W} / \mathrm{m}^{2}$.

The PIRs also arrive calibrated and this changes with time, but more importantly, the calibration done at the Eppley factory is unsatisfactory for field work. As shown by Albrecht and Cox (1976), there are errors in the response of the instrument due to differences in the temperature of the dome and sink. Differential heating of the dome and sink can occur often in the field especially under partly cloudy conditions. The difference in mass of the dome and sink make the dome faster to respond to changes in heating. A careful, blackbody calibration was done for these instruments, including this effect. The absolute accuracy of a PIR is taken to be $10 \mathrm{~W} / \mathrm{m}^{2}$ again from Duda, et. al. (1991), but there is evidence that instruments calibrated together have a much better relative accuracy.

Even after careful calibration, there are field conditions beyond our control that result in the recording of incorrect values. The stations were left relatively 
unattended during much of the field experimental period. During snow events, the radiometer domes become covered, blocking significant amounts of solar energy and providing an opaque longwave emitter. These snow events are easily recognized and eliminated by examining the weather observer records and the daily traces of the various fluxes.

Another problem experienced that requires subjective corrections is frosting of the domes. On clear nights, extreme longwave cooling allows for the temperature of the dome to reach the dew point (frost point) and a layer of ice forms on the domes. This has multiple consequences. It causes the $F_{L W l}$ to increase since the instruments no longer see the cold sky. Instead, they observe an ice layer with an emissivity near unity on the surface of the instrument radiating at or near the ambient temperature. In the morning, the recorded solar radiation may be in error due to the reduction of transmittance due to the frost; later, it can increase by multiple reflections that occur inside the dome, caused by the preferential melting of frost from the south side of the PSP's dome. This would appear in the solar data first as a delay in the onset of sunrise, followed by a sharp increase as the south side melts and the internal reflections occur. Although this effect was observed just after a fresh snowfall, it was not seen under frost conditions.

The longwave fluxes also needed to be corrected since the effects of ice during the nocturnal period were very evident. Adjusting the ice errors was accomplished by continuing the decreasing $\mathrm{F}_{\mathrm{LW} \downarrow}$ curve, predetermined by the 
evening cooling up to the point where the ice began, up until sunrise, when the line was fit to the increasing $F_{\mathrm{LW}}$ curve, determined from the morning heating occurring after the ice melt. 


\section{Observations}

\subsection{Radiation Diurnal Cycle}

An examination of how radiation can affects the stability of the atmosphere requires first an examination of the surface fluxes. Direct comparison of the upwelling fluxes with the downwelling fluxes allows calculations of the power excess or deficit, leading in turn to an understanding in the changes of the local atmosphere.

Section 1.4 showed how boundary layer growth can be related to surface conditions, either through surface moisture, albedo, or latitude. Sky conditions also effect the net fluxes at the surface, thereby affecting the stability. This study collected radiative data over a variety of surface conditions as well as under a variety of cloud conditions. The location of the sites allows an intercomparison for cloud free and cloud present days for both similar surface conditions, snow, as well as for contrasting albedos, after the snow has melted at Grand Junction.

With this in mind, figure 3.1 shows a chronological series of the short wave fluxes under various conditions at Grand Junction. The solid line is the incident (downwelling) solar radiation, $\mathrm{F}_{\mathrm{SW}_{6}}$, and the dashed line is the reflected (upwelling), $F_{\mathrm{SW}}$. Comparison of the horizontal panels shows the differences due to surface albedo. Panel a shows the trace of a cloud free day over snow. The prominent features are the smooth, sinusoidal shape of the solar curve, characteristic of clear days, and the large values for $F_{\text {Sw. }}$. The average albedo of 
a.

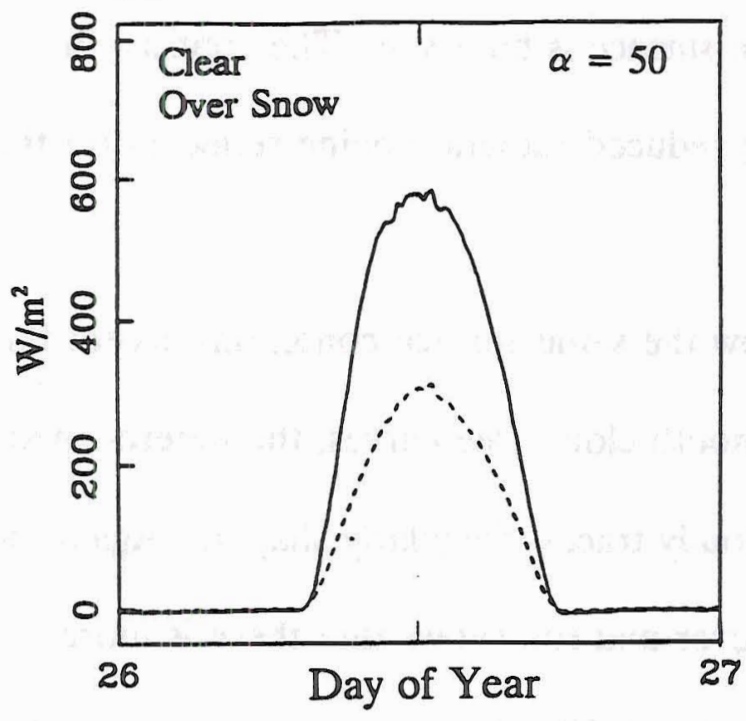

C.

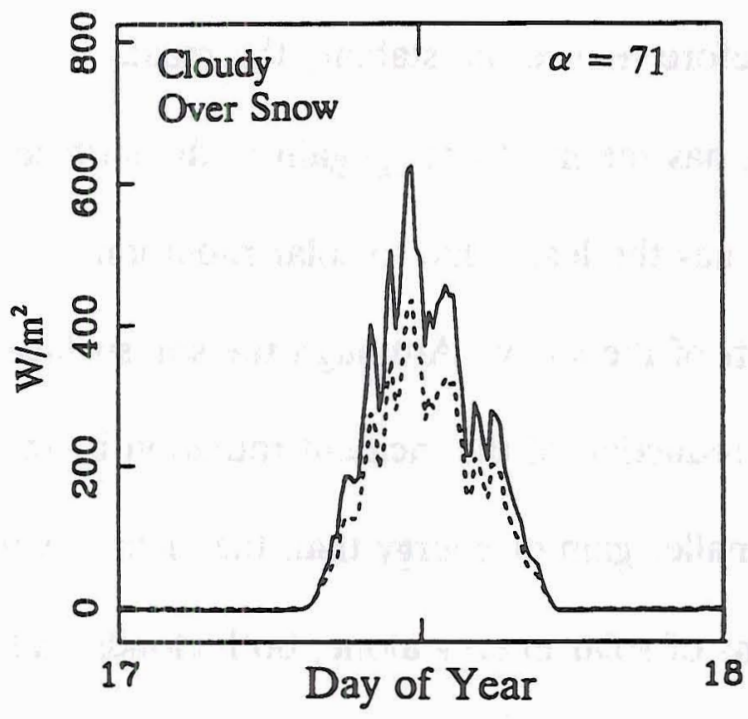

b.

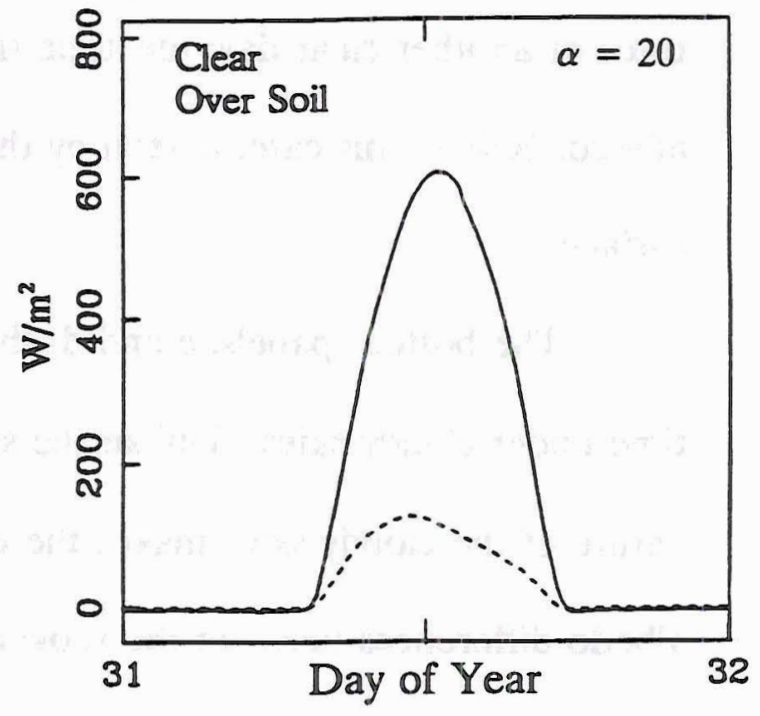

d.

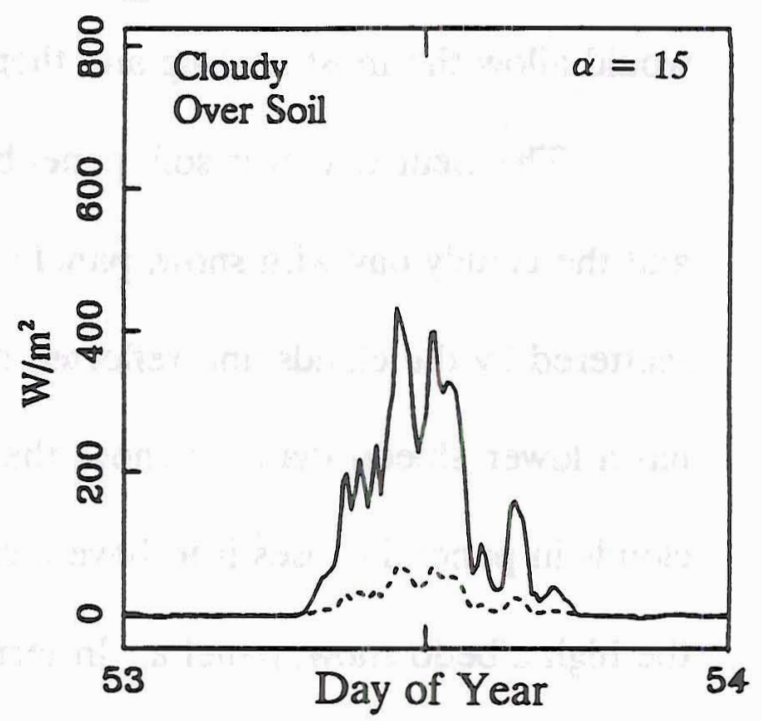

Figure 3.1 Diurnal cycle of shortwave fluxes from Grand Junction. Panel "a" shows a clear day with a snow surface. Panel "b" shows a clear day with a soil surface. Panel "c" shows a cloudy day over a snow surface. Panel "d" shows a cloudy day over soil. 
the day is $50 \%$, a relatively high value due to a recent snowfall. Panel b shows a trace of another clear day; this time the surface is bare soil. The contrast in albedo, $20 \%$ in this case, is seen by the reduced radiation being reflected off the surface.

The bottom panels, $c$ and $d$, show the same surface conditions except this time under cloudy skies. Unlike the smooth cloud free curves, the heterogeneous nature of the cloudy skies makes the cloudy traces irregularly shaped. Again the albedo differences between the snow cover and soil shows that there is more energy being absorbed at the surface with soil. This is not unexpected, but just examining the solar traces is not enough to make a real conclusion as to which day would allow the most heating and therefore reduce the stability the most.

The clear day over soil, panel b, has the most energy gain at the surface, and the cloudy day with snow, panel $\mathrm{c}$, has the least, due to solar radiation scattered by the clouds and reflected off of the snow. Although the soil surface has a lower albedo than the snow, the reduction of the incident radiation by the clouds in panel $d$ causes it to have a smaller gain of energy than the clear day with the high albedo snow, panel a. In terms of solar energy alone, both clouds and snow tend to reduce the amount of energy absorbed at the surface, but clouds appear to have larger effect. To get the complete picture, the longwave fluxes must be examined.

Figure 3.2 shows Grand Junction's longwave (terrestrial) fluxes for the same days as in figure 3.1. Likewise, the $\mathrm{F}_{\mathrm{LW} \downarrow}$ is again the solid line and the 

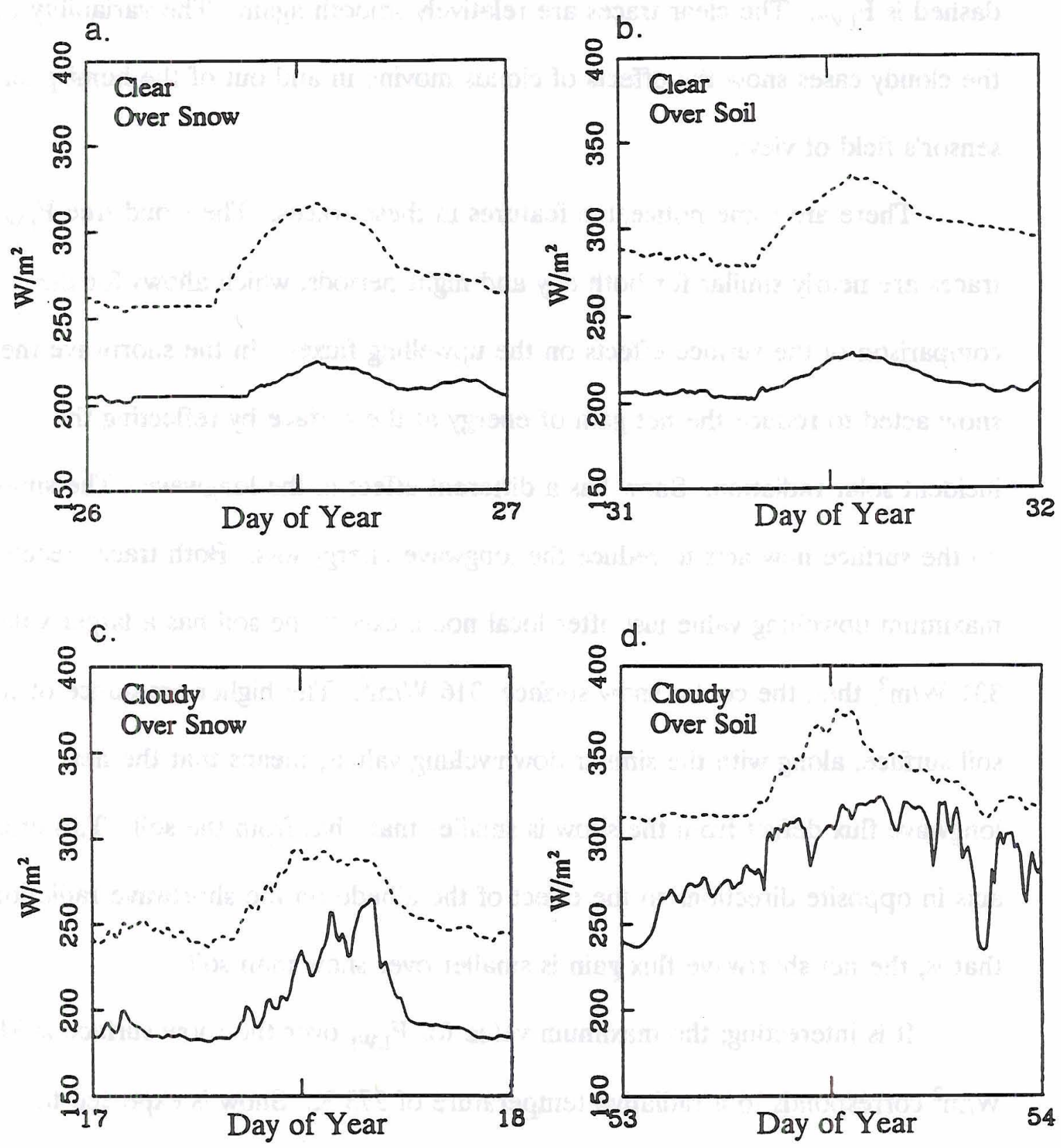

Figure 3.2 Diurnal cycle of longwave fluxes from Grand Junction. Panel "a" shows a clear day with a snow surface. Panel "b" shows a clear day with a soil surface. Panel "c" shows a cloudy day over a snow surface. Panel "d" shows a cloudy day over soil. 
dashed is $F_{L W y}$. The clear traces are relatively smooth again. The variability of the cloudy cases show the effects of clouds moving in and out of the hemispheric sensor's field of view.

There are some noticeable features in these traces. The cloud free $F_{L_{W}}$ traces are nearly similar for both day and night periods, which allows for the comparison of the surface effects on the upwelling fluxes. In the shortwave the snow acted to reduce the net gain of energy at the surface by reflecting the incident solar radiation. Snow has a different effect in the longwave. The snow on the surface now acts to reduce the longwave energy loss. Both traces reach a maximum upwelling value just after local noon, except the soil has a larger value, $331 \mathrm{~W} / \mathrm{m}^{2}$, than the cooler snow surface, $316 \mathrm{~W} / \mathrm{m}^{2}$. The higher emittance of the soil surface, along with the similar downwelling values, means that the net longwave flux deficit from the snow is smaller than that from the soil. This effect acts in opposite directions to the effect of the albedo on the shortwave radiation, that is, the net shortwave flux gain is smaller over snow than soil.

It is interesting; the maximum value for $F_{\mathrm{LW} \uparrow}$ over the snow surface is 316 $\mathrm{W} / \mathrm{m}^{2}$ corresponds to a radiative temperature of $273 \mathrm{~K}$. Snow is expected to remain at a temperature at or below $273 \mathrm{~K}$. In fact, the PIRs at Grand Junction never registered above $316 \mathrm{~W} / \mathrm{m}^{2}$ until the DOY 28 , the day after the last day of snow at the site. These results give increased confidence in the PIR's values.

In addition to having a smaller maximum value for clear days, the snow surface's emitted longwave radiation drops faster in the afternoon and evening 
and remains lower throughout the entire 24 hour period than the soil. By looking only at the longwave net fluxes, the soil surface would have a greater loss of energy than the snow surface over the day.

The cloudy case shows the inhomogeneity of clouds by the variations in the $\mathrm{F}_{\mathrm{LW} !}$. The snow surface shows a partly cloudy sky that appears to clear up during the nocturnal hours. Overcast skies and a lower or warmer cloud are most likely responsible for the higher values of downwelling longwave flux for the soil case. Either way, the soil is receiving a larger average $F_{L w !}$ than the snow surface in this comparison. As in the clear case, the upwelling trace shows that the soil reaches a much warmer temperature and hence emits more radiation than the snow surface. In the cloudy comparison, it appears that the longwave energy loss is greater over snow than over soil, opposite to the clear case. A quantitative study of the total energy balance at the surface is presented next.

\subsection{Integrated Daily Fluxes}

The clear traces show that the soil surface has a larger net gain of solar energy; it also has a larger longwave loss. A knowledge of how the surface albedo effects the net energy budget is not intuitive from an examination of the traces. With clouds present, the questions become even more complex. There are many variables affecting the surface fluxes: albedo of the cloud, albedo of the soil, temperature and thickness of the cloud. Which variables take precedence? This question can be answered by direct intercomparison of data from Grand Junction 
and Meeker. Performing an integration of the radiation streams for various days representing the variety of surface and sky conditions allows a quantitative picture of the net radiation at the surface.

Twelve days with similar sky conditions at both sites were chosen to allow intercomparison, then separated into one of four categories based on those sky conditions, clear or cloud present, and surface, snow or soil at the Grand Junction site. Integration of $F_{N}$ was then computed for a 24 hour period starting at sunrise. Tables 3.1 through 3.4 show the result for selected days. The SW Day, LW Day and Net Day are the sunrise to sunset total integrated energy in $\mathrm{MJ} / \mathrm{m}^{2}$ for the shortwave, longwave and the combination of both respectively. Due to the advancement of the sun as the year progressed the sunrise to sunset length changed from 9.5 hours at the beginning of the experiment to 10.8 hours at the end of the experiment. The LW Night and 24 hour Net are the sunset to sunrise longwave energy gain and sunrise to sunrise net energy gain both also in units of $\mathrm{MJ} / \mathrm{m}^{2}$. Negative values represent an energy loss.

Table 3.1 shows a direct comparison between Meeker and Grand Junction for similar surface conditions. Both sites have high albedos as a result of snowcover. Thinning snowcover caused the albedos at Grand Junction to be higher for DOY 26 and 27; DOY 28 was reported the last day with snowcover at Grand Junction. The high albedos have caused the shortwave radiation absorbed at the surface to be relatively small, an average of $4.8 \mathrm{MJ} / \mathrm{m}^{2}$ at Meeker and 5.5 $\mathrm{MJ} / \mathrm{m}^{2}$ at Grand Junction. During the day, the surface also loses energy through 
Table 3.1 Integrated energy input, $\mathrm{MJ} / \mathrm{m}^{2}$; clear skies both sites over snow

\begin{tabular}{l|ccc||c||ccc||c||}
\cline { 2 - 8 } \multicolumn{1}{c|}{} & \multicolumn{4}{c|}{ Meeker (clear, snow) } & \multicolumn{4}{c|}{ Grand Junction (clear, snow) } \\
\cline { 2 - 8 } \begin{tabular}{|} 
Day Of \\
Year
\end{tabular} & 16 & 26 & 27 & AVG & 16 & 26 & 27 & AVG \\
\hline Albedo & 0.68 & 0.57 & 0.56 & 0.60 & 0.71 & 0.50 & 0.47 & 0.56 \\
\hline SW Day & 3.5 & 5.2 & 5.6 & 4.8 & 3.3 & 6.5 & 6.7 & 5.5 \\
\hline LW Day & -2.4 & -2.8 & -2.9 & -2.7 & -2.7 & -3.0 & -3.1 & -2.9 \\
\hline Net Day & 1.1 & 2.4 & 2.7 & 2.1 & 0.6 & 3.5 & 3.6 & 2.6 \\
\hline LW Night & -2.2 & -3.1 & -3.5 & -2.9 & -3.0 & -2.9 & -3.3 & -3.1 \\
\hline 24 hr. Net & -1.1 & -0.7 & -0.8 & -0.8 & -2.4 & +0.6 & +0.3 & -0.5 \\
\hline
\end{tabular}

longwave cooling, as the radiation emitted by the snow surface is greater than the longwave radiation incident on it from the atmosphere. The values of daytime longwave cooling are similar between the two sites intercomparing each day, with Grand Junction no more than $0.3 \mathrm{MJ} / \mathrm{m}^{2}$ larger for a given day. Combining the daytime values, on the average, both stations have a net gain of energy during the daylight hours, $2.1 \mathrm{MJ} / \mathrm{m}^{2}$ at Meeker and $2.6 \mathrm{MJ} / \mathrm{m}^{2}$ at Grand Junction. After sunset, the shortwave no longer contributes to the energy gain at the surface and only the longwave deficit of energy continues. On average, the surface loss during the night time, $2.9 \mathrm{MJ} / \mathrm{m}^{2}$, is larger than the daytime net energy gain. This results in the system losing energy over the 24 hour cycle.

The next table, table 3.2, intercompares the different albedos at Grand Junction and Meeker for the time period when the surface at Grand Junction was bare. Meeker again is covered in snow, but the sun has advanced, the snow has 
Table 3.2 Integrated energy input, $\mathrm{MJ} / \mathrm{m}^{2}$; clear skies soil at Grand Junction

\begin{tabular}{l|ccc||c||ccc||c|}
\cline { 2 - 8 } \multicolumn{1}{c|}{$\begin{array}{l}\text { Day Of } \\
\text { Year }\end{array}$} & \multicolumn{4}{c|}{ Meeker (clear, snow) } & \multicolumn{3}{c|}{ Grand Junction (clear, soil) } \\
\cline { 2 - 9 } & 30 & 31 & 37 & AVG & 30 & 31 & 37 & AVG \\
\hline Albedo & 0.49 & 0.51 & 0.47 & 0.49 & 0.27 & 0.20 & 0.12 & 0.20 \\
\hline SW Day & 7.0 & 6.5 & 7.2 & 6.9 & 9.1 & 10.5 & 11.4 & 10.3 \\
\hline LW Day & -2.8 & -3.2 & -3.5 & -3.2 & -3.1 & -3.4 & -3.8 & -3.5 \\
\hline Net Day & 4.2 & 3.3 & 3.7 & 3.7 & 6.0 & 7.1 & 7.6 & 6.8 \\
\hline LW Night & -3.4 & -3.6 & -3.0 & -3.4 & -4.0 & -4.0 & -4.1 & -4.0 \\
\hline 24 hr. Net & 0.8 & -0.3 & 0.7 & 0.3 & 2.0 & 3.1 & 3.5 & 2.8 \\
\hline
\end{tabular}

aged, and possibly some Russian rye has emerged; consequently, the absorbed solar radiation is greater than the data in table 3.1. Grand Junction has absorbed a great deal more solar radiation with the low albedo that is associated with the soil surface. The downwelling longwave energy is similar over both surfaces for these clear days. The warmer surface of the soil gives Grand Junction a larger upwelling longwave and causes the net daytime loss to be larger than that of Meeker, but not enough to overpower the difference in solar gain. In this case, the net daytime energies are very different between Meeker and Grand Junction, 3.7 $\mathrm{MJ} / \mathrm{m}^{2}$ versus $6.8 \mathrm{MJ} / \mathrm{m}^{2}$. During the nighttime hours, the warmer soil at Grand Junction continues to make for a larger longwave loss than the cooler snow surface. But even this is not enough to make up for the extra absorbed solar, and while Meeker still has very close to a zero net radiation for the day, Grand Junction gains $2.8 \mathrm{MJ} / \mathrm{m}^{2}$ over the 24 hour period. 
Clouds add another dimension to the surface net radiation. Table 3.3 contains the data from cloudy days while both stations are snow covered. Immediately, the double effects of albedo are apparent. The daytime solar radiation values are smaller than for the clear case, only 2.1 and $2.8 \mathrm{MJ} / \mathrm{m}^{2}$ for Meeker and Grand Junction respectively. This is due to the clouds first scattering much of the incident radiation, and secondly, the snow surface reflecting away a

Table 3.3 Integrated energy input, $\mathrm{MJ} / \mathrm{m}^{2}$; cloudy skies snowcover at both sites

\begin{tabular}{|c|c|c|c|c|c|c|c|c|}
\hline \multirow{2}{*}{$\begin{array}{l}\text { Day Of } \\
\text { Year }\end{array}$} & \multicolumn{4}{|c|}{ Meeker (cloud, snow) } & \multicolumn{4}{|c|}{ Grand Junction (cloud, snow) } \\
\hline & 12 & 17 & 23 & AVG & 12 & 17 & 23 & AVG \\
\hline Albedo & .68 & .73 & .74 & .72 & .75 & .71 & .62 & .69 \\
\hline SW Day & 2.7 & 1.8 & 1.6 & 2.1 & 1.6 & 2.6 & 4.2 & 2.8 \\
\hline LW Day & -1.1 & -1.2 & -0.5 & -1.0 & -1.4 & -1.9 & -2.1 & -1.8 \\
\hline Net Day & 1.6 & 0.6 & 1.1 & 1.1 & 0.2 & 0.7 & 2.1 & 1.0 \\
\hline LW Night & -2.3 & -2.4 & -2.2 & -2.3 & -2.4 & -3.1 & -2.5 & -2.7 \\
\hline 24 hr. Net & -0.7 & -1.8 & -1.1 & -1.2 & -2.2 & -2.4 & -0.4 & -1.7 \\
\hline
\end{tabular}

large percentage of what does pass through the cloud. The daytime longwave cooling is reduced at both stations by the relatively warm clouds. The daytime longwave loss only being $1.0(1.8) \mathrm{MJ} / \mathrm{m}^{2}$ at Meeker (Grand Junction). The effect is net daytime gain is positive and small, about $1 \mathrm{MJ} / \mathrm{m}^{2}$. The nocturnal cooling is also reduced due to the presence of clouds, but the effect is small for this sample 
of days. Cloudy days were determined by examination of the solar data, and hence, any clearing in the night hours might allow for more longwave loss than would be expected from an entirely overcast night. This is likely the case here, since the nocturnal longwave loss is of the same size, 2.2 to $3.1 \mathrm{MJ} / \mathrm{m}^{2}$, as compared to the clear nights, 2.2 to $3.5 \mathrm{MJ} / \mathrm{m}^{2}$. The net integrated flux for the 24 hour period is negative over both sites, $-1.2(-1.7) \mathrm{MJ} / \mathrm{m}^{2}$ at Meeker (Grand Junction). Although more negative than the clear days, the vales are still relatively small.

Table 3.4 contrasts the differences in surface albedo including the effects of clouds. The albedo effects of the surface are seen in the net daytime radiation. Meeker, still snow covered, has a slightly smaller average albedo than in table 3.3. Even with the advance of the sun causing more incident daytime solar radiation, as well as the lower albedo, Meeker still has a very small net solar gain at 2.6 $\mathrm{MJ} / \mathrm{m}^{2}$ that is close to the other value under clouds, $2.1 \mathrm{M} . J / \mathrm{m}^{2}$. The extremely low albedo at Grand Junction, $12 \%$, makes for a large difference in the solar absorbed at the surface. Grand Junction receives a shortwave net of $5.4 \mathrm{MJ} / \mathrm{m}^{2}$ as compared to the snow case where it received only $2.8 \mathrm{MJ} / \mathrm{m}^{2}$. The daytime longwave energy loss is again hindered by the presence of clouds. Values being only $0.8 \mathrm{MJ} / \mathrm{m}^{2}$ at Meeker and $1.1 \mathrm{MJ} / \mathrm{m}^{2}$ for Grand Junction. The reduced albedo at Grand Junction makes the daytime net energy absorbed about 4 times larger than in the cloudy case over snow. This sample of days has a larger suppression of the nocturnal cooling, 1.0 and $1.5 \mathrm{MJ} / \mathrm{m}^{2}$ as compared to 2.3 and 
2.7 MJ/m². Clouds remained longer after sunset, increasing the downwelling longwave radiation during the night. The result is that the net energy in Meeker is small and positive $\left(0.8 \mathrm{MJ} / \mathrm{m}^{2}\right)$, while the low albedo soil causes the Grand Junction to have a net energy gain as large as the clear days, $2.8 \mathrm{MJ} / \mathrm{m}^{2}$.

Table 3.4 Integrated energy input, $\mathrm{MJ} / \mathrm{m}^{2}$; cloudy skies soil at Grand Junction

\begin{tabular}{l|rrr||r|rrr||c||}
\cline { 2 - 8 } \multicolumn{1}{c|}{} & \multicolumn{4}{c|}{ Meeker (cloud, snow) } & \multicolumn{4}{c|}{ Grand Junction (cloud, soil) } \\
\cline { 2 - 9 } \multicolumn{1}{c|}{$\begin{array}{l}\text { Day Of } \\
\text { Year }\end{array}$} & 39 & 41 & 53 & AVG & 39 & 41 & 53 & AVG \\
\hline Albedo & .79 & .57 & .67 & .68 & .11 & .11 & .15 & .12 \\
\hline SW Day & 1.2 & 4.1 & 2.4 & 2.6 & 3.9 & 7.1 & 5.2 & 5.4 \\
\hline LW Day & -0.3 & -1.5 & -0.7 & -0.8 & -0.8 & -1.9 & -1.5 & -1.1 \\
\hline Net Day & 0.9 & 2.6 & 1.7 & 1.8 & 3.1 & 5.2 & 3.7 & 4.3 \\
\hline LW Night & -0.4 & -1.6 & -1.0 & -1.0 & -0.9 & -1.8 & -1.7 & -1.5 \\
\hline 24 hr. Net & 0.5 & 1.0 & 0.7 & 0.8 & 2.2 & 3.4 & 2.0 & 2.8 \\
\hline
\end{tabular}

Clear skies have a greater net daytime energy input and also a larger longwave cooling during the night. The soil allows for a greater amount of energy to be absorbed at the surface, for the clear days the energy is considerable, nearly $7 \mathrm{MJ} / \mathrm{m}^{2}$. If all of this energy were used to heat a boundary layer to neutrality, it would be enough to destroy a $7 \mathrm{~K} / \mathrm{km}$ stable layer of $1400 \mathrm{~m}$ depth. Barrier height to the west is less than this value and even under the strongest stability, the mixing would be great enough to completely destroy the stable layer and reconnect the free atmosphere with the surface air. But, for clear skies over snow the net energy gain over 24 hours is either positive or negative, but always close to 
zero. When the surface is soil, the net energy gain is positive and larger,

\section{$2.8 \mathrm{MJ} / \mathrm{m}^{2}$.}

Table 3.4 shows the effects of clouds. Although there is less incident solar radiation due to the albedo of the clouds, their presence also hampers the longwave cooling. The snowcovered sample of days in table 3.3 , have negative energy gains for the 24 hour period. The energy gains are negative and slightly larger than the other days, most likely from the nocturnal cooling that was not suppressed as much as would be expected from overcast skies during the night. When the clouds remained throughout the night and hindered the nocturnal longwave loss, the net energy gain over snow was positive and closer to zero, $\left(0.8 \mathrm{MJ} / \mathrm{m}^{2}\right)$. Over soil, the clouds reduction of the incident solar radiation was not strong enough to keep the extremely low albedo from allowing a large 24 hour net gain of energy, $2.8 \mathrm{MJ} / \mathrm{m}^{2}$.

\subsection{Surface Moisture Effects}

Examination of the net fluxes alone does not tell the complete story. The sensible heat flux is the controlling factor in determining whether a stable layer will become more stable or less stable. Section 1.4 showed the net flux striking the earth can go into sensible heat $(H)$, latent heat (LE) or ground (G) fluxes. Snow is a good insulator. It has a low thermal conductivity, and heat capacity. When the ground is snowcovered, $Q_{G}$ is approximately zero. $\mathbb{Q}_{G}$ is approximated to zero when over soil as well, this is not true for any given instant, but over a 24 
hour period this is probably a good approximation. Whiteman (1992) showed in Arizona during a 10 day period in January, the average daily ground storage was on the order of $0.25 \mathrm{MJ} / \mathrm{m}^{2}$. The data taken in Grand Junction and Meeker were taken during the same season as the Whiteman data, and at a higher latitude; the estimate of the ground storage being on the order of $0.25 \mathrm{MJ} / \mathrm{m}^{2}$ is a conservative one.

Bowen ratios, the ratio of sensible heat to latent heat, are assumed according to Stull (1988), in order to determine the sensible heat fluxes. Stull lists typical values of Bowen ratio from 5.0 over arid regions to 0.1 over the seas, including 0.5 for grasslands and 0.2 for irrigated orchards. Abundant surface moisture is available through the entire experiment, either through snowcover or the water remaining after the snow melts, so Bowen ratios of 0.15 and 0.5 are chosen to examine the effects of moisture on energy available for boundary layer growth. Right under the instruments the value might be close to 0.15 , but it is important to try to get a value that pertains to the entire valley system, including the rocks and trees, etc., so the higher value, 0.5 , will be used as well.

The sensible heat flux using the Bowen ratio method are calculated during the daylight hours. For the nocturnal period, the $F_{L w}$ is assumed to all go into a sensible heat flux away from the surface. The daytime integrated sensible heat fluxes and the 24 hour integrated sensible heat fluxes are reported. This will give a quantitative idea of the ability of different sky and surface conditions to maintain or destroy surface stable layers. The results are presented in tables 3.5 and 3.6. 
Table 3.5 Sensible Heat Flux assuming Bowen ratio of 0.15.

\begin{tabular}{|c|c|c|c|c|}
\hline \multicolumn{2}{|c|}{ Sensible Heat Flux MJ/m² } & \multirow{2}{*}{$\begin{array}{l}\beta=.15 \\
\text { Daytime }\end{array}$} & \multirow{2}{*}{$\begin{array}{r}\text { Meeker } \\
0.3 \\
\end{array}$} & \multirow{2}{*}{$\begin{array}{c}\begin{array}{c}\text { Grand } \\
\text { Junction }\end{array} \\
0.3 \\
\end{array}$} \\
\hline Clear & Snow at both & & & \\
\hline & & Net Total & -2.6 & -2.6 \\
\hline & Soil at Grand & Daytime & 0.5 & 0.9 \\
\hline & Jur & Net Total & -2.9 & -3.1 \\
\hline \multirow[t]{4}{*}{ Cloudy } & \multirow{2}{*}{$\begin{array}{c}\text { Snow at both } \\
\text { sites }\end{array}$} & Daytime & 0.1 & 0.1 \\
\hline & & Net Total & -2.2 & -2.6 \\
\hline & \multirow{2}{*}{$\begin{array}{l}\text { Soil at Grand } \\
\text { Junction }\end{array}$} & Daytime & 0.2 & 0.6 \\
\hline & & Net Total & -0.8 & -0.9 \\
\hline
\end{tabular}

Table 3.6 Sensible Heat Flux assuming Bowen ratio of 0.5.

\begin{tabular}{|c|c|c|c|c|}
\hline \multicolumn{2}{|c|}{ Sensible Heat Flux $\mathrm{MJ} / \mathrm{m}^{2}$} & $\beta=.5$ & Meeker & Grand \\
\hline \multirow[t]{4}{*}{ Clear } & \multirow{2}{*}{$\begin{array}{c}\text { Snow at both } \\
\text { sites }\end{array}$} & Daytime & 0.7 & 0.8 \\
\hline & & Net Total & -2.2 & -2.1 \\
\hline & \multirow{2}{*}{$\begin{array}{l}\text { Soil at Grand } \\
\text { Junction }\end{array}$} & Daytime & 1.2 & 2.3 \\
\hline & & Net Total & -2.2 & -1.7 \\
\hline \multirow[t]{4}{*}{ Cloudy } & \multirow{2}{*}{$\begin{array}{c}\text { Snow at both } \\
\text { sites }\end{array}$} & Daytime & 0.4 & 0.3 \\
\hline & & Net Total & -1.9 & -2.4 \\
\hline & \multirow{2}{*}{$\begin{array}{l}\text { Soil at Grand } \\
\text { Junction }\end{array}$} & Daytime & 0.6 & 1.4 \\
\hline & & Net Total & -0.4 & -0.1 \\
\hline
\end{tabular}


The results of these tables are remarkable. The shaded boxes are the net integrated sensible heat flux, in $\mathrm{MJ} / \mathrm{m}^{2}$, for the entire day, sunrise to sunrise. The daytime boxes are the sensible heat flux for the daylight hours only, sunrise to sunset. These daytime values, positive, represent the flux from the surface to the atmosphere and thus represent the energy available to build boundary layers and destabilizing the atmosphere. The largest values are those for Grand Junction when the surface is soil. This is regardless of the Bowen ratio chosen or sky condition. Using the higher Bowen ratio, less evaporation, there is significant daytime heating that can occur. In these examples either 2.3 or $1.4 \mathrm{MJ} / \mathrm{m}^{2}$, the higher value corresponding to the clear days. This sensible energy will build larger boundary layers than the smaller energies found over snow, but they will not be deep enough to reconnect the local atmosphere with the free atmosphere aloft. Unfortunately, the experiment was only able to examine the soil surface after the natural snow melt, and hence later in the winter season. By this time, the sun has progressed farther North and the incident solar radiation is larger than during the earlier portion of the experiment. In addition, the large values of energy occur only for the larger Bowen ratio, less evaporation. This ratio of 0.5 may be too large in this case, especially since the snow has just recently melted away, this would falsely elevate the daytime values of sensible heat flux.

During this winter time period, the daytime heating is small and the net energy gain at the surface is negative. As a result, the daytime heating is small enough to keep from reconnecting the surface from the free atmosphere; 
Table 3.7 Average Net Heat Flux by surface and sky type Heat Flux $\mathrm{MJ} / \mathrm{m}^{2} / \mathrm{day}$ Snow Soil

\begin{tabular}{|c|c|}
\hline \multicolumn{1}{|c}{ Clear } & Cloudy \\
\hline-2.2 & $-1.6(-0.7)$ \\
\hline-1.7 & -0.1 \\
\hline
\end{tabular}

therefore, the atmosphere will continue to stabilize night after night during these winter months. Clouds reduce the solar incident at the surface and also reduce the longwave cooling that can occur during the day. Again assuming the Bowen ratio of 0.5 , the net 24 hour integrated sensible heat flux results are arranged into the four categories, snow, soil, clear and cloudy, in table 3.7. It is evident that the clear days have a larger loss of sensible energy than do the cloudy days. This is possible mainly because of the large portion of the daytime $F_{N}$ being used in latent heating for the clear days. In addition, extreme cooling occurs during the night because of the cloud free skies allowing a large value of the $F_{L W}$. The clouds reduce the incident shortwave flux, and at the same time hinder the longwave cooling; the result is a very small daytime integrated sensible heat gain. The cloudy, snowcovered 24 hour integrated sensible heat flux of $-1.6 \mathrm{MJ} / \mathrm{m}^{2}$ is probably too large for a completely cloudy night. The longwave cooling during the these nights are of the same magnitude as the clear nights, implying that the clouds may have been thin or scattered during the night. If an average longwave cooling from the other cloudy nights (table 3.4), nights assumed to be overcast or mostly cloudy, are used, the resulting 24 hour integrated heat flux is closer to 
zero $\left(0.7 \mathrm{MJ} / \mathrm{m}^{2}\right)$ and the effect of the diminished nocturnal cooling by clouds is more readily apparent.

From this data, over soil, under clear skies, a large cooling occurs resulting in a stabilizing of the atmosphere. These conditions, left undisturbed, would tend to form cold air masses, and deep stable layers. When clouds are present, the net energy loss is negative, but smaller in magnitude. This regime would not tend to form stable layers; but, if the clouds appeared above an already stable atmosphere, they would not tend to destroy it.

\subsection{Cumulative Integrated Fluxes}

The previous sections showed how the surface fluxes of energy and sensible heat are affected for particular days. What happens over a series of consecutive days with changing sky conditions and surface conditions? How does the system respond? Figure 3.3 is a graph of the daily integrated net flux, $Q_{N}$, for each day of the experiment. During the early part of the experiment up to day 23, Grand Junction and Meeker are both losing energy from the surface over the 24 hour period, except Grand Junction has a net loss averaging $1 \mathrm{MJ} / \mathrm{m}^{2}$ larger than Meeker. Grand Junction begins to have positive energy gains after day 26 and Meeker follows on day 29. For the remainder of the experiment Grand Junction has a net gain of energy at the surface and Meeker fluctuates between positive and negative energy gains. After day 23, the net gain at Grand Junction, apart 


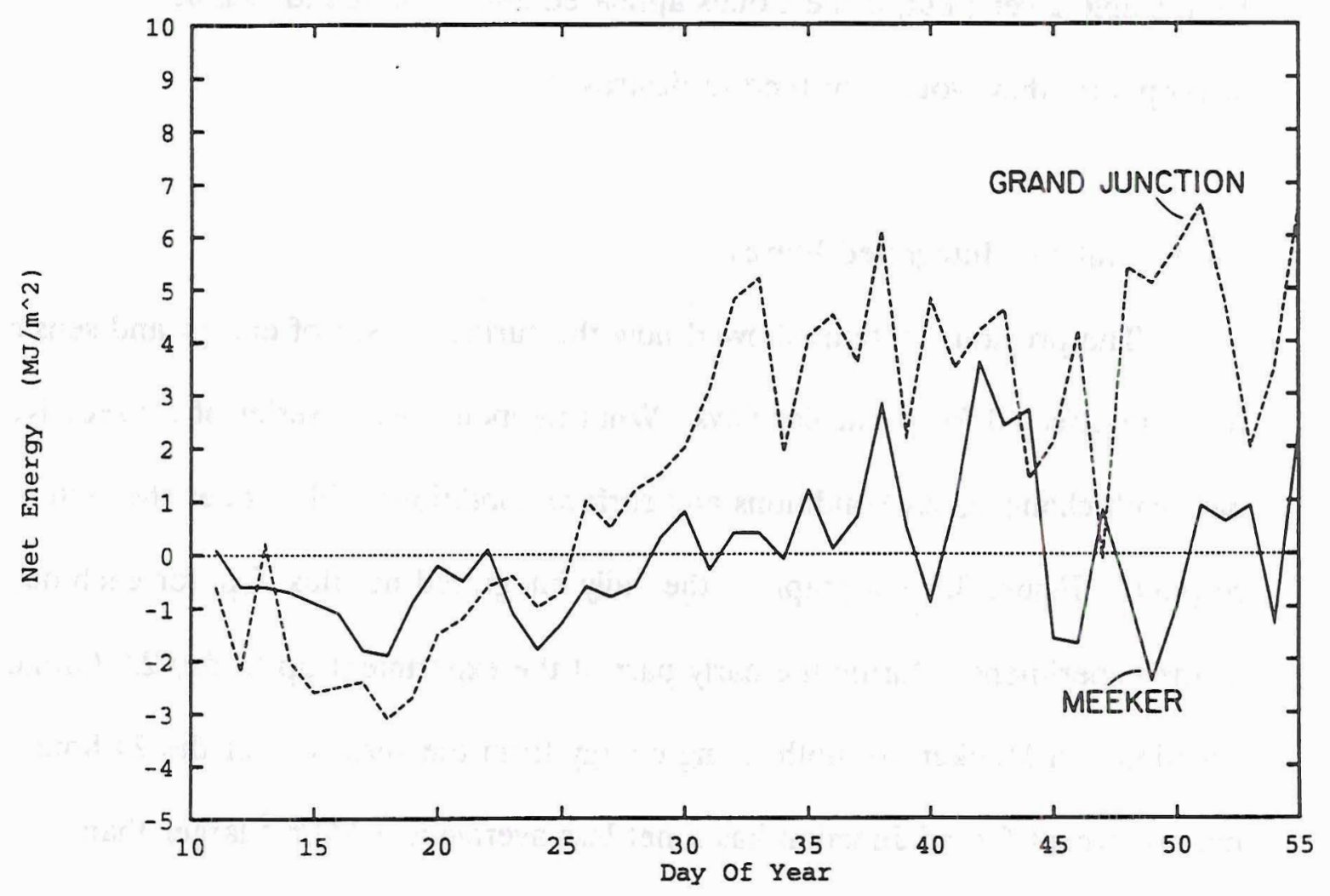

Figure 3.3 Net integrated 24 hour flux versus day of year for Meeker and Grand Junction. 
from very overcast days 44 and 47 , is larger than Meeker. This is expected from the larger $F_{\text {Sw }}$ after day 26 as the surface becomes soil at Grand Junction.

Figure 3.4 shows another way to examine the surface fluxes. This is a plot of the cumulative net flux at the surface. It is calculated every ten minutes. The diurnal cycle of energy gain during the day and energy loss during the night is evident. The solid trace shows Grand Junction, the dashed line Meeker. Grand Junction cools until DOY 23 and reaches a minimum value of about $-24 \mathrm{MJ} / \mathrm{m}^{2}$. Meeker cools until DOY 28 and reaches the minimum value near $-15 \mathrm{MJ} / \mathrm{m}^{2}$. After this, Meeker holds steady, only gaining $6.8 \mathrm{MJ} / \mathrm{m}^{2}$ of energy between DOY 28 and 41 , an average of only $0.5 \mathrm{MJ} / \mathrm{m}^{2} /$ day. During the same time period, Grand Junction has gained $47.3 \mathrm{MJ} / \mathrm{m}^{2}$ of energy, an average of $3.6 \mathrm{MJ} / \mathrm{m}^{2} /$ day. This is a direct result of the increased $F_{\mathrm{Sw}}$ at Grand Junction, shown in the plot of daily cumulative $\mathrm{F}_{\mathrm{sw}}$, figure 3.5. At the end of the experiment, Meeker still has a negative total energy gain; Grand Junction has a positive and large net energy gain of almost $100 \mathrm{MJ} / \mathrm{m}^{2}$.

To examine the cooling of the atmosphere, Bowen ratios are again introduced. Figures 3.6 and 3.7, show the cumulative sensible heat flux for Grand Junction and Meeker respectively. The Bowen ratios of $0.15,0.5,1.0$, and $\infty$ are chosen. An infinite Bowen ratio means all energy goes into sensible heat flux and none is used in latent heating. To produce the graph, daily daytime $\mathrm{Q}_{\mathrm{N}}$ is calculated and used in equation 10 to get $Q_{\text {HDaytime }}$ this is added to the $F_{L W}$ nighttime to get a $Q_{H}$ for 24 hours and accumulated over the experimental period. 


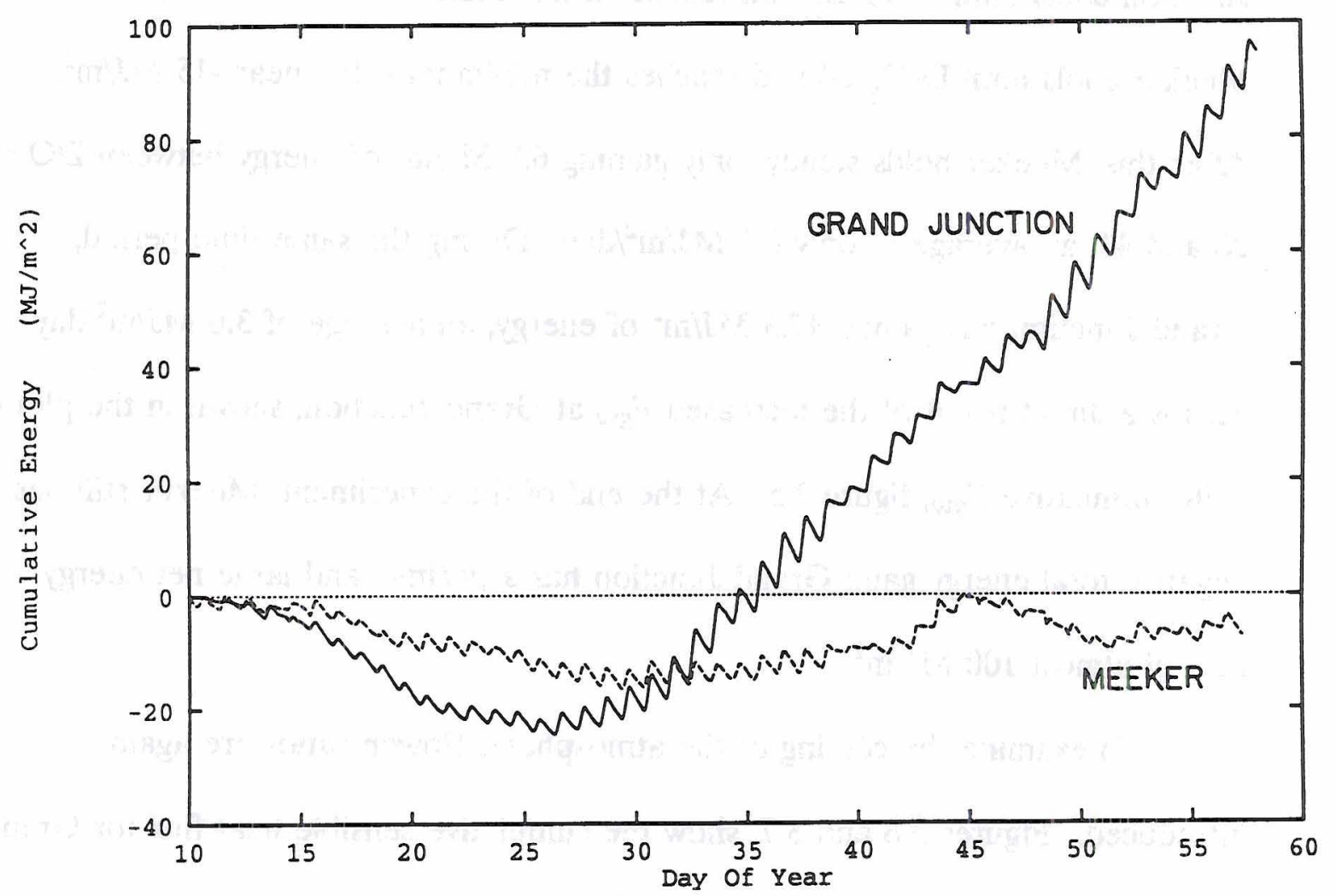

Figure 3.4 Cumulative net energy calculated every ten minutes versus day of year for Meeker and Grand Junction. 


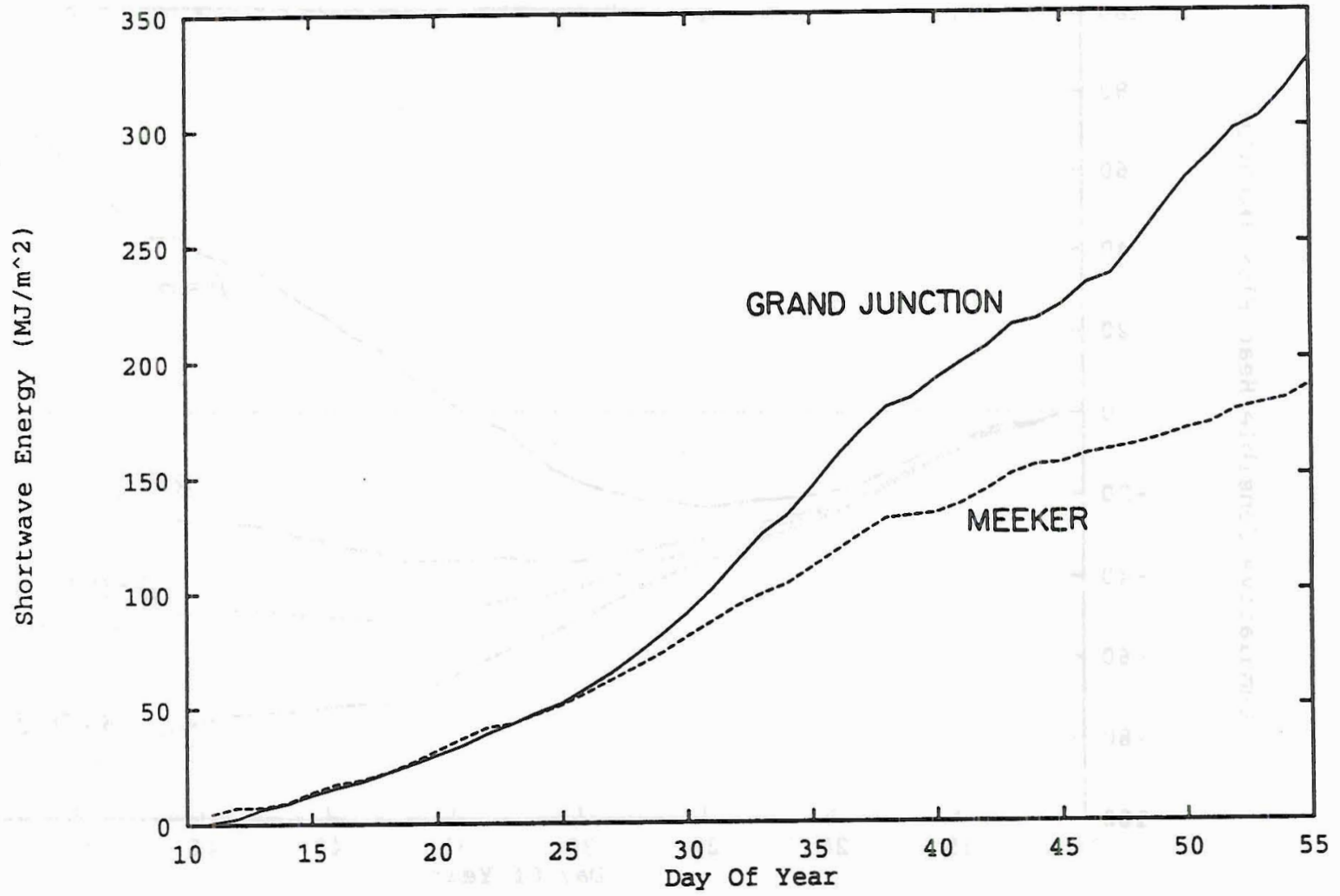

Figure 3.5 Cumulative daily shortwave radiation versus day of year for Meeker and Grand Junction. 


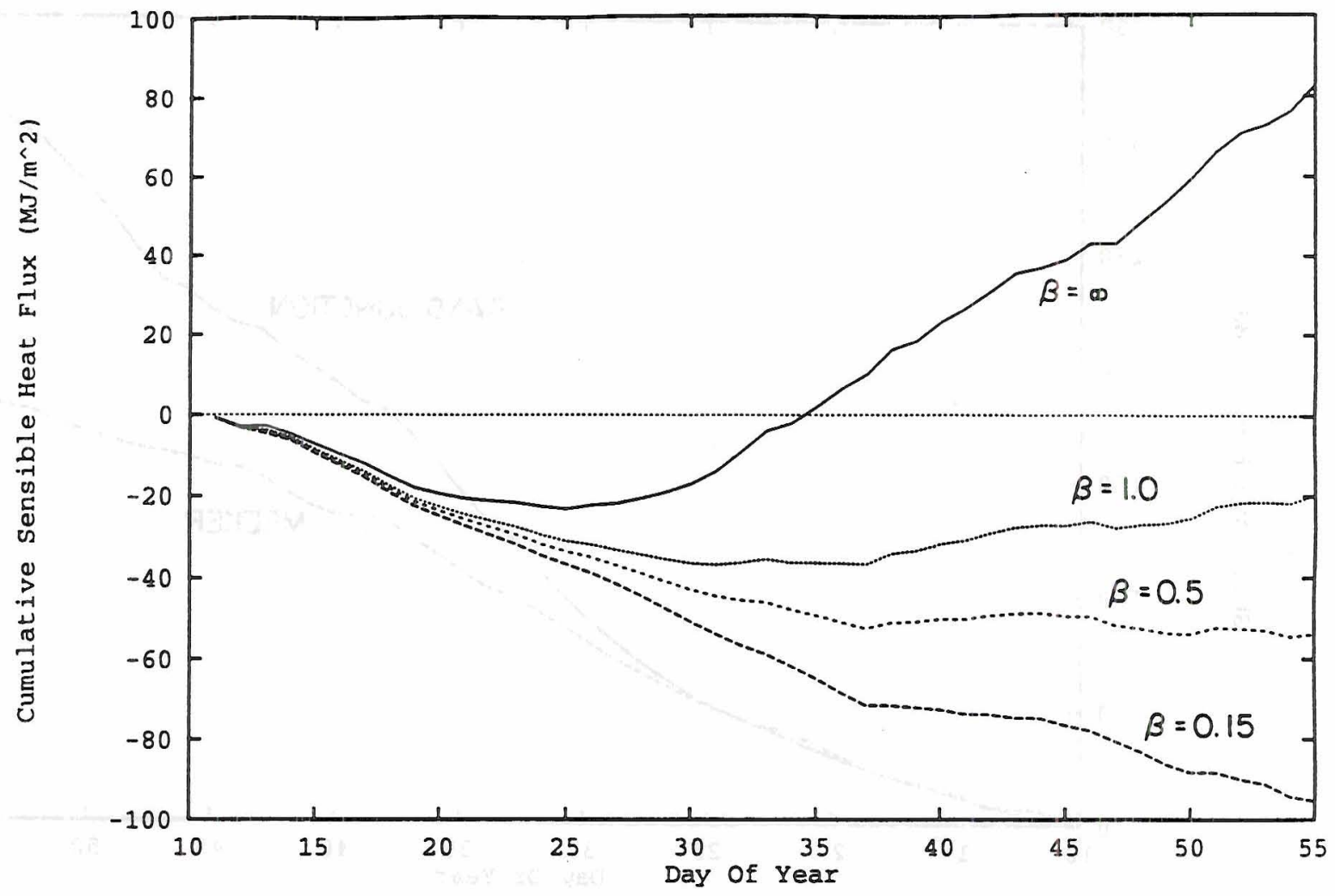

Figure 3.6 Cumulative daily sensible heat flux versus day of year at Grand Junction for various Bowen ratios. 


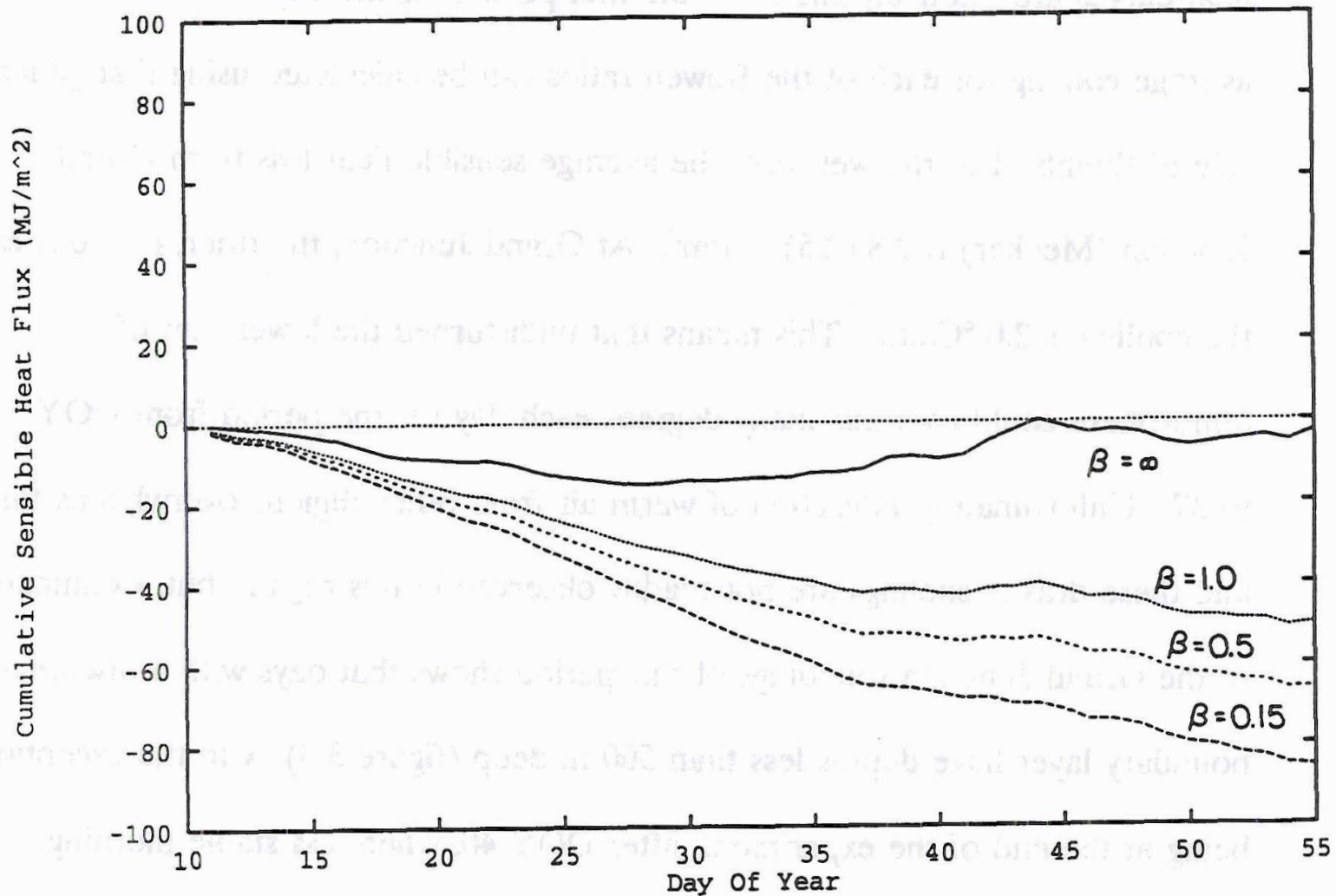

Figure 3.7 Cumulative daily sensible heat flux versus day of year at Meeker for various Bowen ratios. 
Over a very wet area, $\beta=0.15$, there is not a positive average sensible heat flux for either station. When a drier surface is chosen, $\beta=0.5$, Both stations cool until about day 37, when Grand Junction begins a relatively stationary period and meeker starts a less rapid cooling.

A general rule of thumb is that $1 \mathrm{MJ} / \mathrm{m}^{2}$ of energy can raise the temperature of a $1 \mathrm{~km}$ column of air $1{ }^{\circ} \mathrm{C}$. The slopes of the cumulative sensible heat curves are relatively linear for the first portion of the experiment and the average cooling for each of the Bowen ratios can be calculated using that general rule of thumb. For the wet case, the average sensible heat loss from Grand Junction (Meeker) is $2.8(2.5) \mathrm{MJ} / \mathrm{m}^{2}$. At Grand Junction, the drier, $\beta=0.5$, case the cooling is $2.0^{\circ} \mathrm{C} / \mathrm{day}$. This means that undisturbed the lowest $\mathrm{km}$ of atmosphere could cool this many degrees each day for the period from DOY 11 to 37 . Unfortunately, advection of warm air from other regions overwhelms this and these drastic coolings are not readily observed in this region; but, examination of the Grand Junction soundings of this period shows that days with a discernable boundary layer have depths less than $500 \mathrm{~m}$ deep (figure 3.8), with the exceptions being at the end of the experiment, after DOY 40 , when less stable morning soundings and lower albedo in the region helped build deeper boundary layers. Several days did not have a mixed boundary layer and are not included in figure 3.8. These days had either missing sounding data or were stable in the lower layers due to clouds or larger scale disturbances. These depths will not be deep enough to recouple the lower atmosphere with free atmosphere above. These 


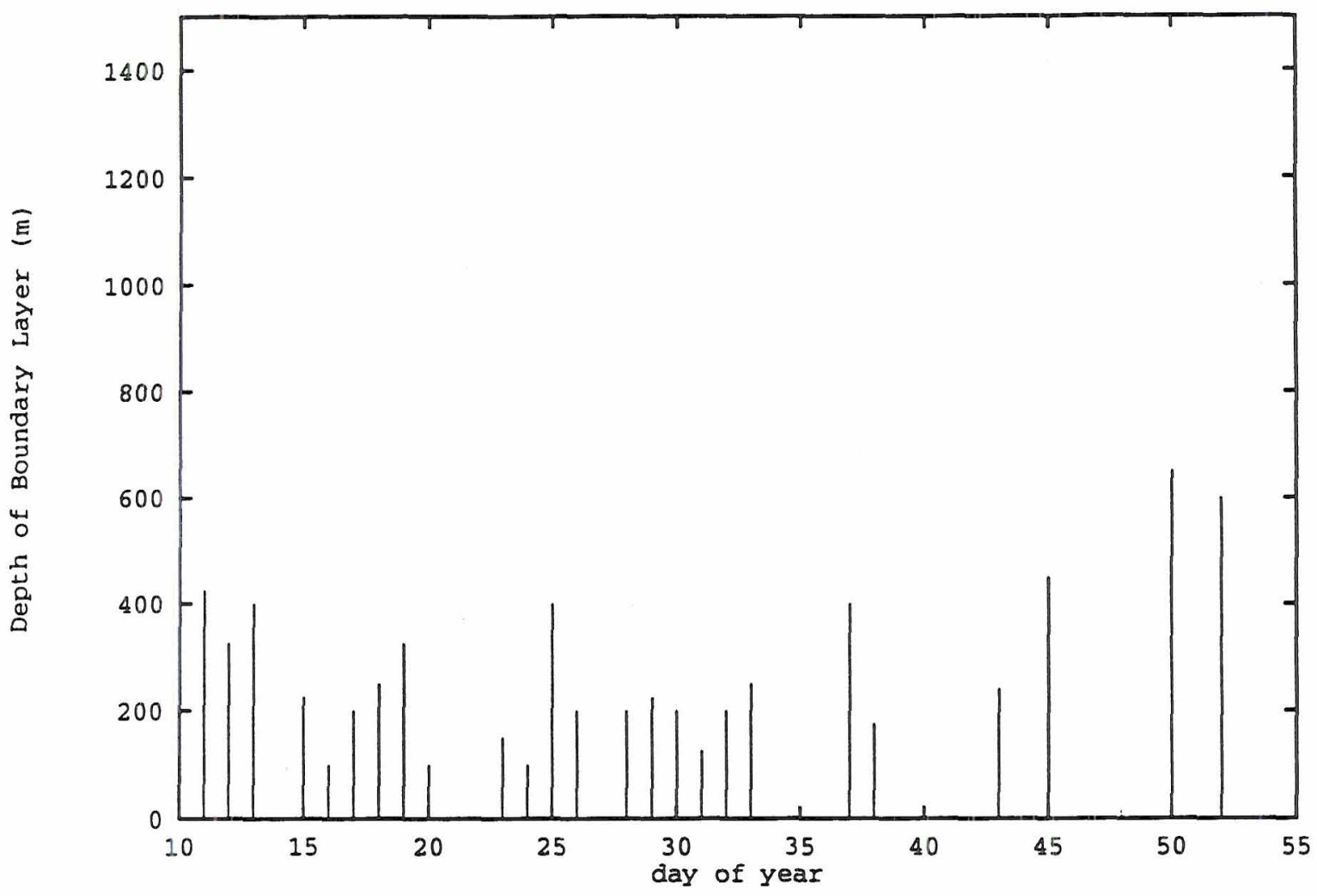

Figure 3.8 Depth of boundary layer from the 00 UTC Grand Junction sounding versus Day of Year. 
graphs do show that even with a large energy gain at the surface, the average daily sensible heat flux is negative, or very small over this period. 


\section{Modelling Studies}

The next section of the study concentrates on the ability of models to reproduce the observed radiation fields. Two models are used, a broadband longwave model by Cox (Smith et al. 1990) and a two stream shortwave model by Stackhouse (1991). Several comparisons were done. Both models were tested against the ground truth at Grand Junction during the experimental time, and the top of the atmosphere for the historical data set taken by ERBE.

\subsection{Broadband Infrared flux model}

A broadband infrared radiative transfer model by Cox (Smith et al. 1990) was used for long wave comparisons. This is an updated version of the model first described in Quart. J. R. Met. Soc., 1973. The new model considers $\mathrm{H}_{2} \mathrm{O}, \mathrm{CO}_{2}$ and $\mathrm{O}_{3}$ as the important emitters of the atmosphere. Plane parallel, infinite, grey body clouds can be included in the radiative calculations and are parameterized by a mass absorption coefficient and the liquid water content at the top and base of the cloud.

In this study, to get profiles of the important gasses, the National Weather Service radiosonde soundings from Grand Junction were collected. The $\mathrm{CO}_{2}$ was assumed uniformly mixed throughout the atmosphere having a value of $0.5 \mathrm{~g} / \mathrm{kg}$. Ozone was taken from the U.S. Standard Midlatitude Winter Atmosphere (McClatchey et al. 1972). Not all soundings were complete, and additionally, the 
weather service does not record dew points above $300 \mathrm{hPa}$; therefore, any missing data was interpolated from the Standard Atmosphere and used in the calculations.

\subsubsection{Downwelling Comparison}

The downwelling comparisons were done during the experimental period. The radiosonde sounding time was matched with the PIR data and a direct comparison of the two could be made. Comparing relatively instantaneous values of downwelling radiation, as opposed to daily averages, cloudy conditions could be compared as well. For the comparison, the days deemed to be overcast were chosen to better approximate a semi-infinite cloud deck. Clear days were again chosen by the smooth sinusoidal solar curve. Results are shown in Figures 4.1 and 4.2.

Figure 4.1 is the comparison of the broadband model versus the measured PIR flux at the surface for clear days. The observed fluxes are all larger than the calculated fluxes. This could be due to some local warmer clouds or possibly some of the relatively warmer valley walls being in the inside the hemispheric view of the PIR. The solid line represents a perfect one to one correspondence between the calculated and observed fluxes. This line shows a good correspondence between the calculated and observed, with only a pair of outliers.

The comparison between the modeled cloud and the real atmosphere is difficult. Problems arise. First, the real cloud is not realistically represented; the cloud layer was determined subjectively. A skew-T diagram was examined to 


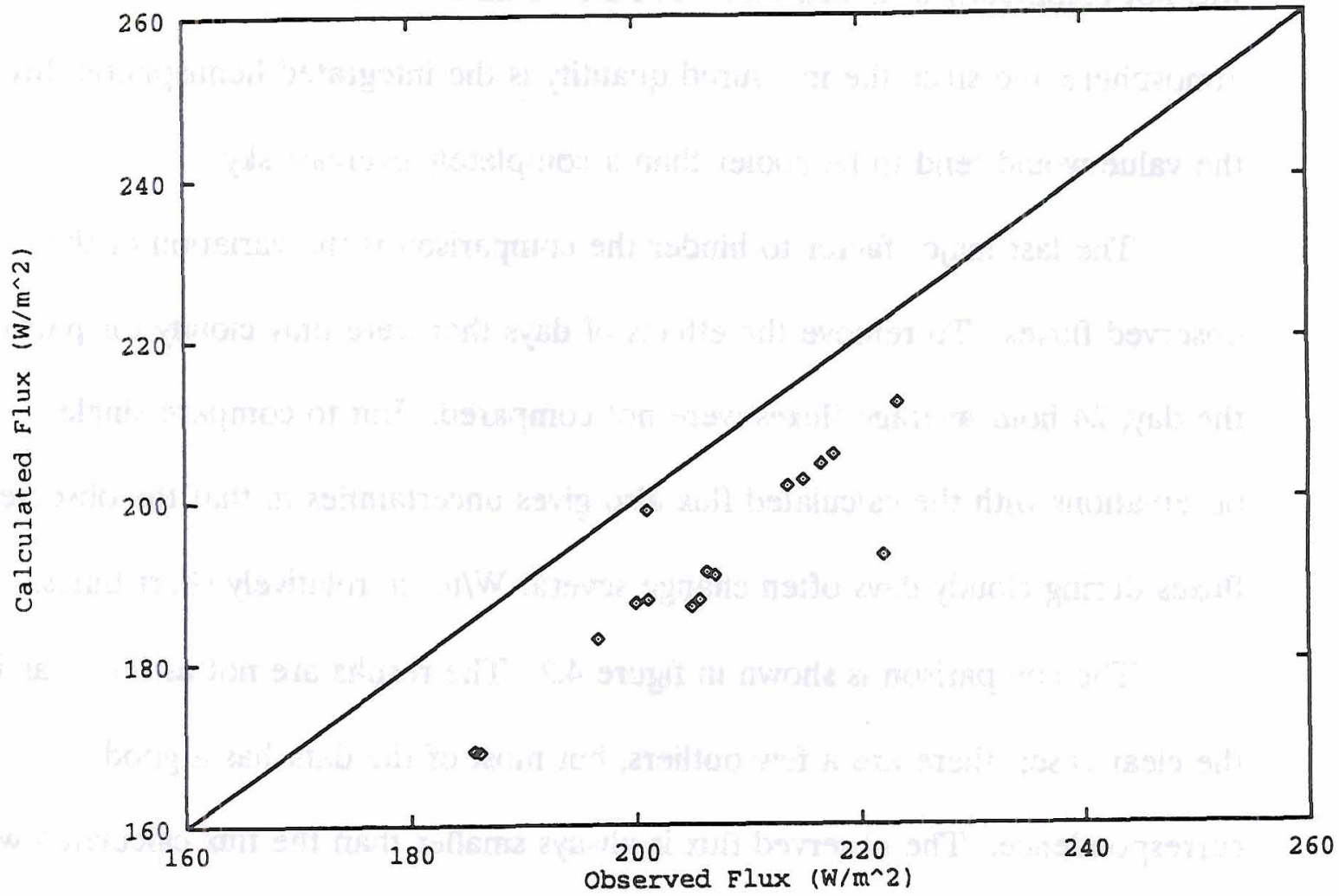

Figure 4.1 Broadband model calculated longwave downwelling surface flux versus the instrument observed flux for clear days. 
decide where the layer starts and stops. Problems with the resolution of the diagram can give different values of cloud top and base liquid water content, in turn affecting the fluxes computed by the model.

The model cloud is plane parallel and infinite in extent. Real clouds have variations in both thickness and horizontal extent. This may account in part for the poorer correspondence between the observed and calculated fluxes. If the sky was not completely overcast, then the PIR would be able to see the cooler atmosphere and since the measured quantity is the integrated hemispheric flux, the value would tend to be cooler than a completely overcast sky.

The last major factor to hinder the comparison is the variation of the observed fluxes. To remove the effects of days that were only cloudy for part of the day, 24 hour average fluxes were not compared. But to compare single observations with the calculated flux also gives uncertainties in that the observed fluxes during cloudy days often change several $\mathrm{W} / \mathrm{m}^{2}$ in relatively short times.

The comparison is shown in figure 4.2. The results are not as linear as in the clear case; there are a few outliers, but most of the data has a good correspondence. The observed flux is always smaller than the flux calculated with the model. This tends to support the fact that the sky is not represented perfectly by the model cloud. The PIR may be observing portions of the cooler sky under mostly cloudy conditions.

All of this into account, the results are not unpromising. In the cloudy case, there are a few outliers and the rest of the days seem to fall into a pretty 


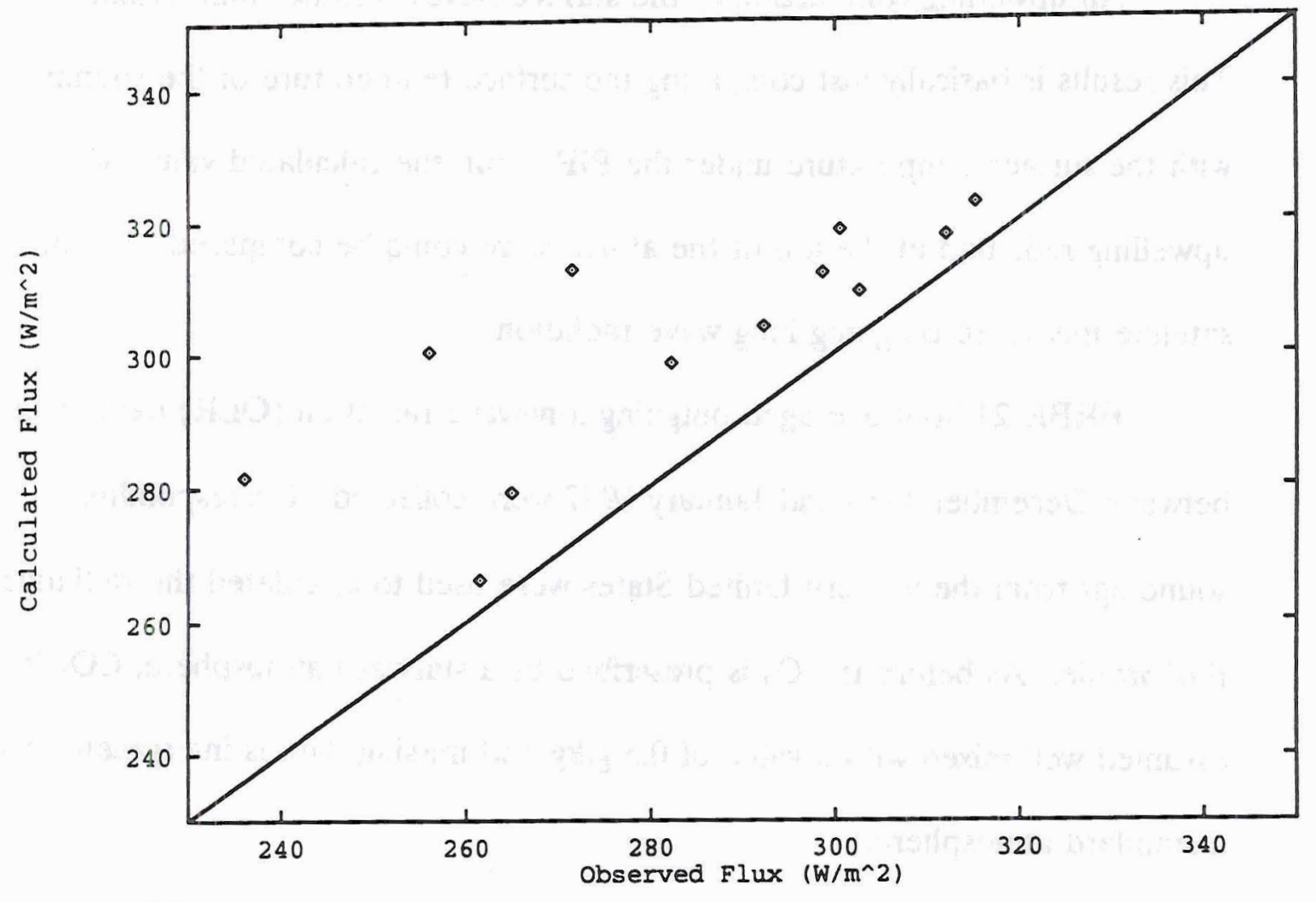

Figure 4.2 Broadband model calculated longwave downwelling surface flux versus the instrument observed flux for cloudy days. 
good correspondence. The clear case has excellent correspondence between the observed and calculated fluxes, except they are offset by about $13 \mathrm{~W} / \mathrm{m}^{2}$. This gives an increased confidence in the observed surface fluxes and in the ability of the model to reproduce those values.

\subsubsection{Upwelling Comparison}

An upwelling comparison of the surface fluxes is rather uninformative. This results is basically just comparing the surface temperature of the sounding with the surface temperature under the PIR. But, the calculated value of upwelling radiation at the top of the atmosphere could be compared with the satellite measured outgoing long wave radiation.

ERBE 24 hour averaged outgoing longwave radiation (OLR) data taken between December 1986 and January 1987 were collected. Corresponding soundings from the western United States were used to calculated the radiative flux profile. As before the $\mathrm{O}_{3}$ is prescribed by a standard atmosphere, $\mathrm{CO}_{2}$ is assumed well mixed with a value of $0.5 \mathrm{~g} / \mathrm{kg}$ and missing data is interpolated from a standard atmosphere.

Only clear days were compared in this portion of the study. The inhomogeneity of clouds in general and especially over the period of 24 hours with model's treatment of clouds as plane parallel and infinite, makes it difficult to try to compare results of the daily soundings to the averaged OLR from the ERBE data. 
Soundings were chosen from several stations to represent the great basin: Winnemucca (WMC), Ely (ELY), Salt Lake City (SLC), the western slope: Grand Junction (GJT), and the high plains: Denver (DEN), Dodge City (DDC), Topeka (TOP), Omaha (OMA), North Platte (LBF). Clear days were identified from the Local Climatological Data (U. S. Department of Commerce 1986 \& 1987) pamphlets. The 00 and 12 UTC soundings were retrieved for these days from the National Center for Atmospheric Research. The broadband model was then run on each of the soundings to compute the flux profiles in the longwave.

Figures 4.3 and 4.4 show the results. The solid line is a perfect one to one correspondence between the ERBE measured OLR and the computed OLR. The dashed lines are shifted plus or minus $9 \mathrm{~W} / \mathrm{m}^{2}$ from a perfect correspondence. In figure 4.3 the results are presented for each sounding's model calculated versus the ERBE daily average flux corresponding to the $2.5^{\circ} \times 2.5^{\circ}$ lat-lon box that encompasses the ground station.

The " $\mathrm{x}$ " represent the 00 UTC soundings and the " + " the 12 UTC soundings. There is a bias for the 00 UTC calculated OLR to be larger than the observed, and similarly the 12 UTC calculated OLR to be smaller than the observation. This is due to the timing of the soundings. The ERBE observational product is the average of the entire day, the calculations pertain to a certain period of the day. Fortunately, for this array of longitudes the 00 UTC sounding corresponds to the afternoon, and the $12 \mathrm{UTC}$ to the morning. By averaging these soundings, the calculated values recreate better the ERBE average values. 


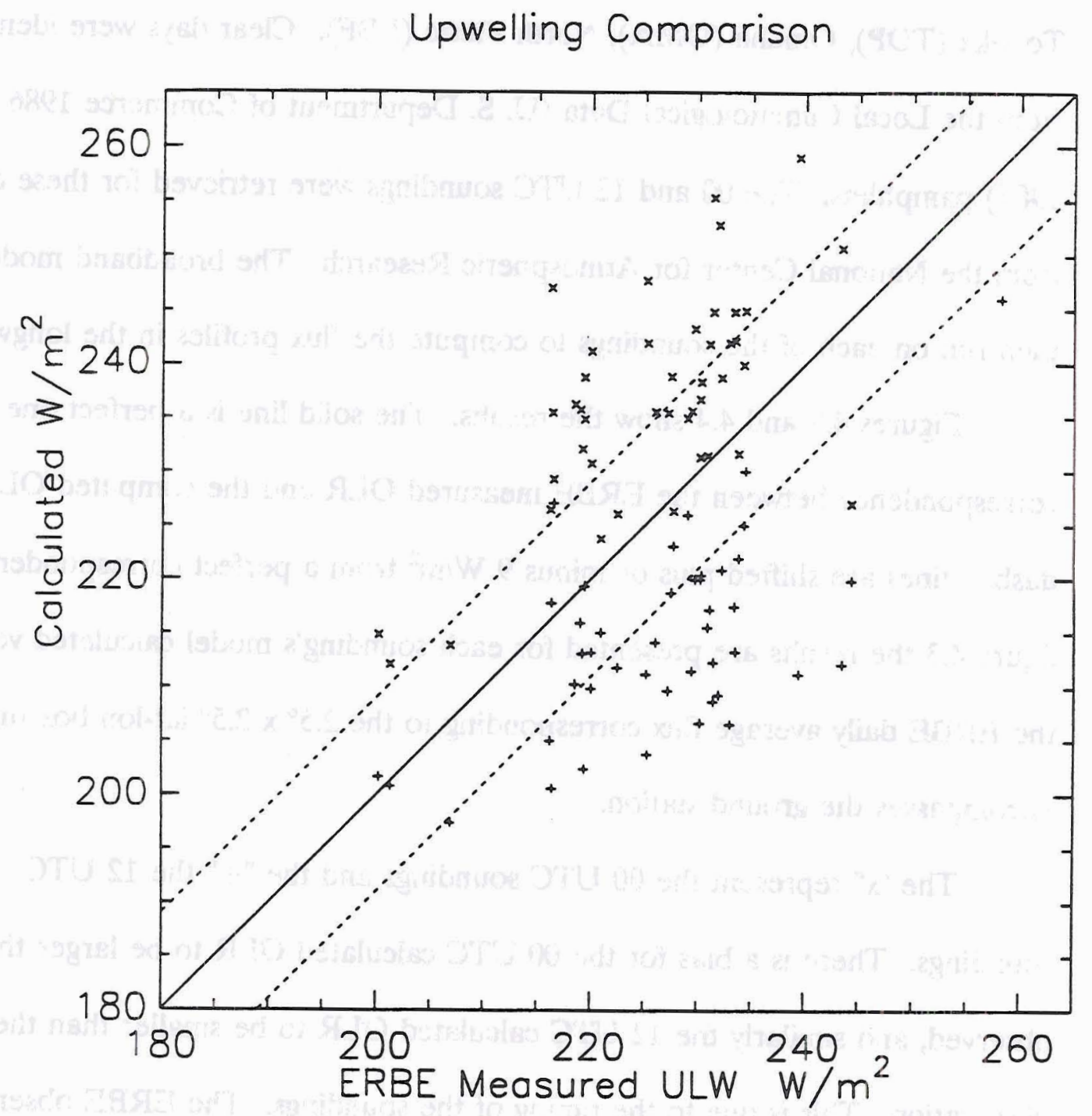

Figure 4.3 Broadband model calculated longwave upwelling top of atmosphere flux versus the ERBE measured flux. Calculations with afternoon soundings are represented with an " $x$ "; morning soundings with a "t". 
Figure 4.4 is the comparison of the computed morning and afternoon sounding OLR averaged versus the ERBE observed. Now almost every data point falls into the range of plus or minus $9 \mathrm{~W} / \mathrm{m}^{2}$. This is even over a large range of values from as low as about $200 \mathrm{~W} / \mathrm{m}^{2}$ to almost as large as $260 \mathrm{~W} / \mathrm{m}^{2}$. While this is only done for clear days, it has shown that the broadband infrared model can give an accurate picture of the OLR.

The broadband infrared model is useful in describing the value of longwave radiation at the surface and at the top of the atmosphere, using only the NWS 00 and 12 UTC soundings.

\subsection{Two Stream Shortwave Model}

A two stream radiative transfer model by Stackhouse(1991) is used in the shortwave region to provide a comparison to the observations. The model includes cloud particle extinction, Rayleigh scattering, gaseous absorption and multiple reflections. It calculates the flux for 14 spectral regions between $0.26 \mu \mathrm{m}$ and $3.5 \mu \mathrm{m}$. For the shortwave cases, comparisons were made to the average radiation over the entire day.

\subsubsection{Downwelling Comparison}

Downwelling comparisons were accomplished with the PSP data from Grand Junction. The total integrated $\mathrm{F}_{\mathrm{SW}_{\downarrow}}$ for a given sunrise-sunset time period was computed and then converted into an average flux over a full 24 hours. The 


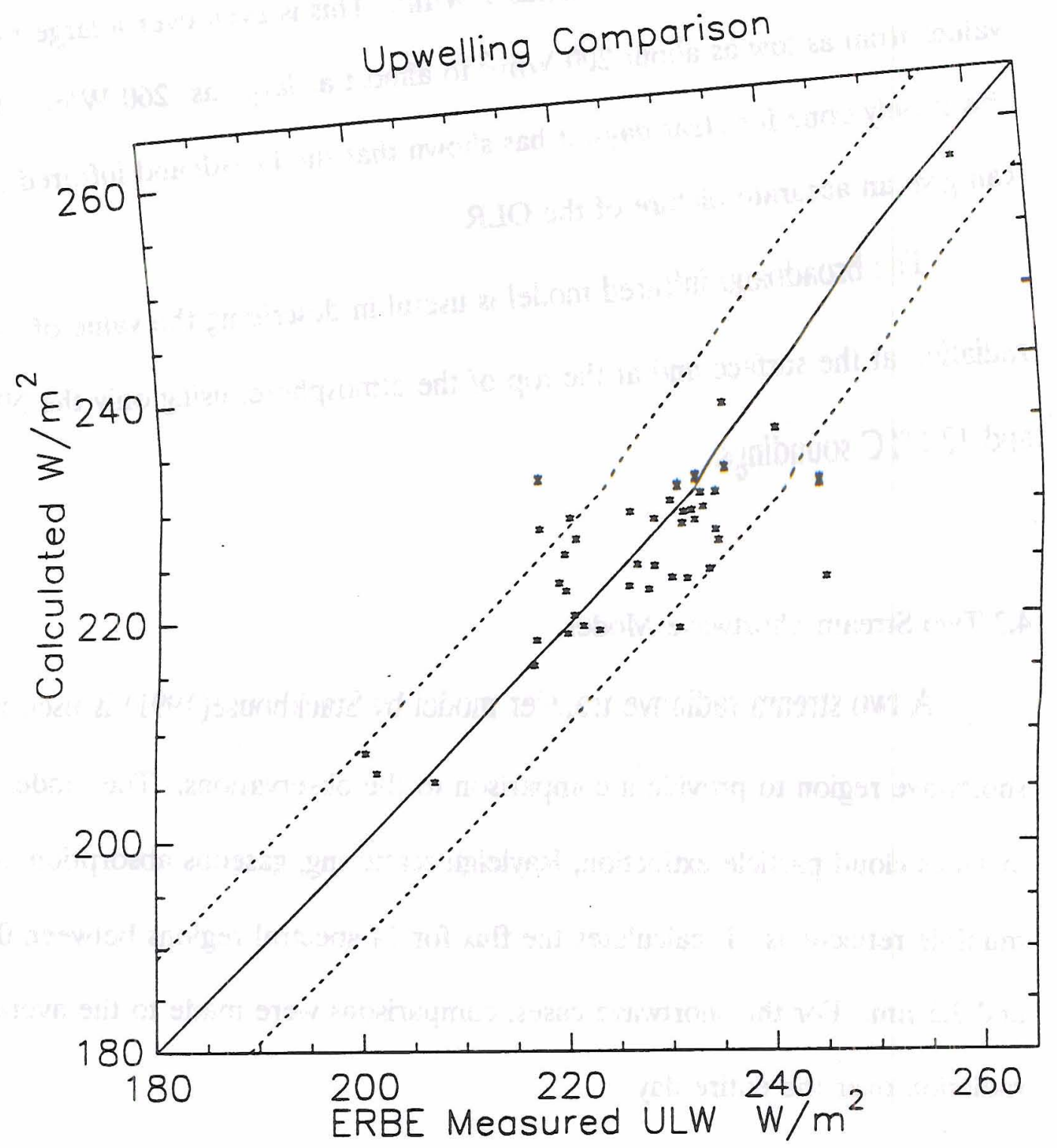

Figure 4.4 Broadband model calculated longwave upwelling top of atmosphere flux versus the ERBE measured flux. The calculated values are the result of averaging the model results for the morning and afternoon soundings. 
stream model. Two soundings correspond to each day of data, and these are both compared to the observed surface flux for the day. Since multiple reflections are accounted for in the two stream model, the albedo input to the model could be important. Since to goal would be to describe the surface flux without an a priori knowledge of the surface albedo, a fixed albedo of 0.3 was used in the model as well as the ground station observed albedo to determine how these differences in albedo would affect the results.

Figure 4.5 has the comparison of the observed downwelling shortwave flux to the flux calculated using the albedo measured at the surface with the ground station. Figure 4.6 is the same except this time a surface albedo of $30 \%$ is assumed for the calculations.

The values agree quite well in both cases. Most of the data points fall in the range of $10 \mathrm{~W} / \mathrm{m}^{2}$. This is not too unexpected, since the examination was only of the clear days. The difference between the albedo calculated with the surface station and the denoted $30 \%$ albedo is small, likely because the albedo at the surface only affects the multiple reflections, which in turn have a small effect on the total downwelling radiation at the surface. A reasonable degree of accuracy can be obtained in calculation the daily averaged $\mathrm{F}_{\mathrm{SW} \downarrow}$ using a NWS sounding and the two stream model. 


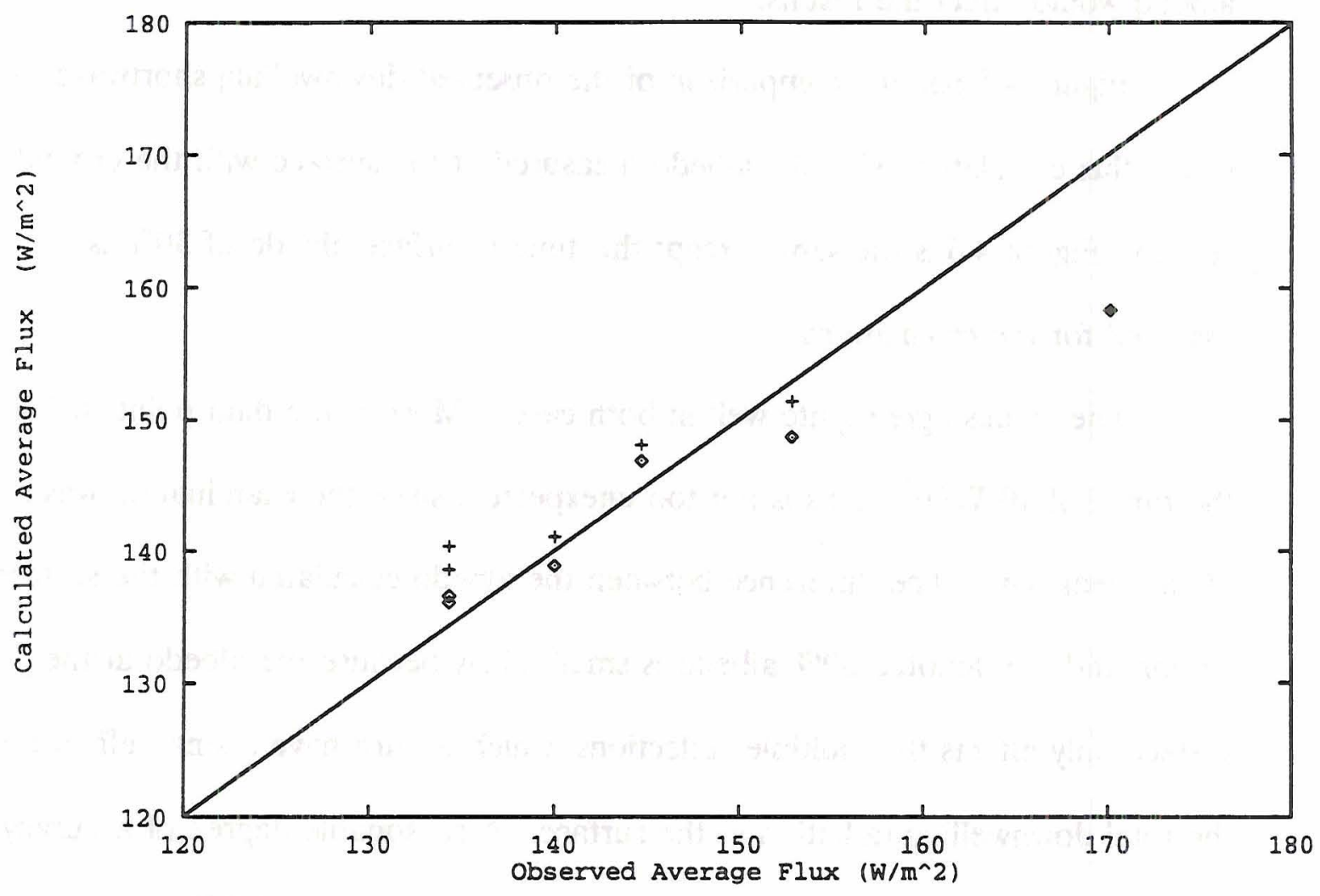

Figure 4.5 Two stream model calculation of surface downwelling shortwave flux versus the instrument observed flux. Model used the instrument observed surface albedo. 


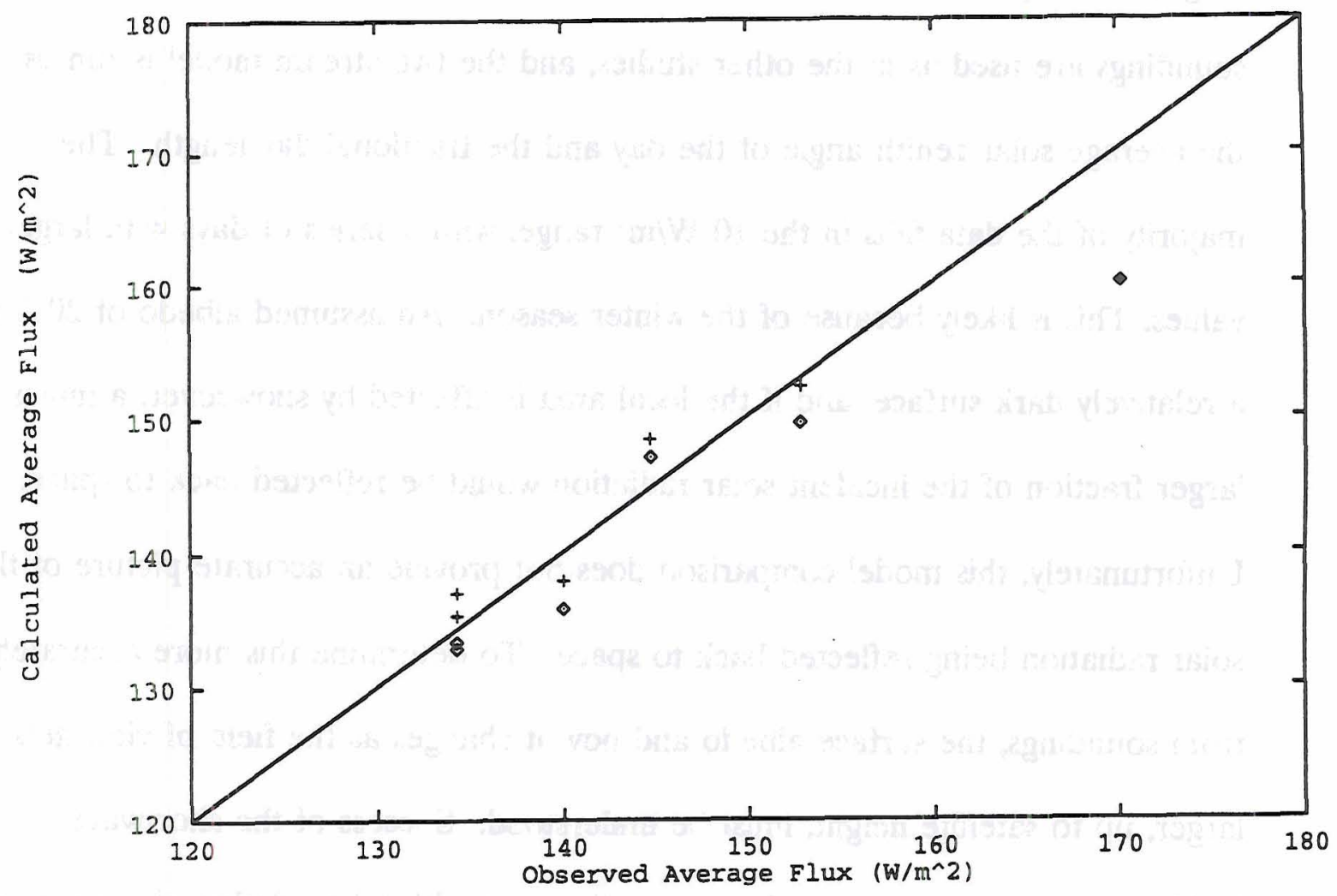

Figure 4.6 Two stream model calculation of surface downwelling shortwave flux versus the instrument observed flux. Model used prescribed 30\% albedo. 


\subsubsection{Upwelling Comparison}

Comparison of the upwelling shortwave radiation is a difficult task. To do so accurately requires a knowledge of the albedo of the surface. This data did not exist for the time period that the ERBE data was available. Without this, approximations are made. Clear days, determined from the Local Climatological Data Summaries, were chosen for all of the same sites that were used in the longwave study. The albedo of the surface is taken to be $20 \%$. The NWS soundings are used as in the other studies, and the two stream model is run using the average solar zenith angle of the day and the fractional day length. The majority of the data falls in the $10 \mathrm{~W} / \mathrm{m}^{2}$ range, with a series of days with larger values. This is likely because of the winter season. An assumed albedo of $20 \%$ is a relatively dark surface, and if the local area is affected by snowcover, a much larger fraction of the incident solar radiation would be reflected back to space. Unfortunately, this model comparison does not provide an accurate picture of the solar radiation being reflected back to space. To determine this more accurately from soundings, the surface albedo and how it changes as the field of view gets larger, up to satellite height, must be understood. Success of the shortwave incident comparison leads to the assumption that with a knowledge of the surface albedo over a large area, the top of the atmosphere flux could be calculated as well, as the same process occur on the exit trip from the atmosphere as occur on the way to the surface. 
While less successful at calculating the top of atmosphere shortwave radiation, the downwelling streams show promise that with a better knowledge of the surface albedo, a knowledge of the shortwave radiation streams could be acquired from simple NWS soundings in conjunction with the two stream model. 


\section{Conclusions}

Direct measurements of the shortwave and longwave fluxes at the surface provided a valuable tool for examining the energy available to affect the atmospheric stability along the western slope of Colorado. An intercomparison between Meeker and Grand Junction showed that the net flux during the day is positive; during the night, it is negative. Both stations showed over snow for the 24 hour period, the net gain of energy at the surface is either positive or negative and close to zero. If the surface is darker, soil covered, the energy gain is slightly larger and positive. There is very little difference between the daily integrated net flux at the surface for clear and cloudy. The reduction of the downwelling shortwave flux by clouds is compensated by the reduced longwave cooling, making the shortwave and longwave each closer to zero, yet retaining the total balance.

The real differences arise when the energy absorbed at the surface during the daylight hours is partitioned into sensible and latent heating. There is abundant surface moisture in the region during the winter months and much of the incident energy is used to change the phase of water, either melting snow, or evaporating water. The Bowen ratio for the valley system, including the rocks and trees, was assumed 0.5 . This value, which provides two thirds of the net radiative flux as latent heat, is consistent with boundary layer depths in this region. A Bowen ratio of 0.15 was also examined as this may be a better value when examining very wet areas like snowfields. Using these assumptions the sensible 
heat available for building boundary layers is severely reduced. Choosing the larger Bowen ratio of 0.5 , the values for daytime sensible heat flux range from 0.3 to $1.2 \mathrm{MJ} / \mathrm{m}^{2}$ over snow, the lower albedo soil has larger yet still small sensible energy, 1.4 to $2.3 \mathrm{MJ} / \mathrm{m}^{2}$. These cumulative sensible heat fluxes will not be large enough to destroy a stable layer during this winter season. These calculations agree with the observed heights of boundary layers to the extent that the stable layers cannot be neutralized by a sensible heat flux during the winter season.

Over 24 hours, the effects of clouds are also evident when the latent heating is considered. It appears that the reduced solar input in combination with the smaller net longwave cooling of the cloudy days, let the clear days tend to have a larger net cooling due to the unhindered nocturnal loss.

The examination of the cumulative net radiative flux and cumulative sensible heat flux shows that Grand Junction receives a positive net radiative flux after the snow melts; but, a net positive 24 hour sensible heat flux is only possible for very dry soil.

The broadband infrared model was shown to produce accurate surface values of the instantaneous downwelling radiation for clear skies. Cloudy skies proved more difficult, but the discrepancies can be explained in terms of the heterogeneous nature of the real sky and the plane parallel, infinite cloud used to model the said cloud. 
In the comparison of the top of the atmosphere, upwelling longwave radiation, the model again did remarkably well when the cooler morning sounding and warmer afternoon sounding were averaged together.

The two stream shortwave model produced good results for the surface downwelling shortwave radiation on clear days. An a priori knowledge of the surface albedo was not necessary for accuracy as the multiple reflections only amount to a small portion of the total incident solar radiation. On the other hand, the calculated upwelling shortwave radiation showed a relatively poor representation of the radiation exiting the atmosphere as determined by the ERBE satellites. The uncertainty of albedo at the surface due to surface type (snow, soil, or mix) causes large differences in the comparison.

The model portion of the study has shown that radiative transfer models in conjunction with NWS standard atmospheric soundings can provide a quantitative description of the longwave radiative streams at the top of the atmosphere and at the Earth's surface and shortwave downwelling flux at the surface.

It appears that during the winter season at $40^{\circ} \mathrm{N}$ along the western slope of Colorado, the solar gain of energy during the day is not sufficient to destroy a stable layer alone. If there is snowcover, and little synoptic interference, the energy balance for the day would tend to create stable layers or increase the strength of stable layers already existing. 


\section{References}

Albrecht, B. and S. K. Cox, 1976: Pyrgeometer Data Reduction and Calibration Procedures. Colorado State University Atmospheric Science Paper No. $251,48 \mathrm{pp}$.

Cox, S. K., 1973: Infra-red heating calculations with a water vapor pressure broadened continuum. Quart. J. R. Met. Soc., 99, 669-679.

Duda, D. P., G. L. Stevens and S. K. Cox, 1991: Microphysical Properties of Marine Stratocumulus from Tethered Balloon Measurements. J. Appl. Met., 30, 170-186.

Mayr, G. 1993: Evolution of Orographic Blocking. Ph.D. Dissertation. Department of Atmospheric Science. Colorado State University. Fort Collins, CO 80523.

McClatchey, R. A., R. W. Fenn, J. E. A. Selby, F. E. Volz, J. S. Garing, 1972: Optical Properties of the Atmosphere, third edition. Environmental Research Paper No. 411, Air Force Cambridge Research Laboratories, Bedford, MA, 108 pp.

Oke, T. R., 1978: Boundary Layer Climates. Halsted Press. 372 pp.

Smith, W. L., P. F. Hein and S. K. Cox, 1990: The 27-28 October 1986 FIRE IFO Cirrus Case Study: In Situ Observations of Radiation and Dynamic Properties of a Cirrus Cloud Layer. Mon. Wea. Rev., 118, 2389-2401.

Stackhouse, P. W. Jr. and G. L. Stevens, 1991: A Theoretical and Observational Study of the Radiative Properties of Cirrus: Results from FIRE 1986. J. Atmos. Sci., 48, 2044- 2059.

Stull, R. B., 1988: An Introduction to Boundary Layer Meteorology. Kluwer Academic Press. 666 pp.

U. S. Department of Commerce, NOAA, 1986: Local Climatological Data: Monthly Summary, Denver, CO; Dodge City, KS; Ely, NV; Grand Junction, CO; North Platte, NE; Omaha, NE; Salt Lake City, UT; Topeka, KS; Winnemucca, NV; December, NCDC, Asheville, North Carolina.

U. S. Department of Commerce, NOAA, 1987: Local Climatological Data: Monthly Summary, Denver, CO; Dodge City, KS; Ely, NV; Grand Junction, 
CO; North Platte, NE; Omaha, NE; Salt Lake City, UT; Topeka, KS; Winnemucca, NV; January, NCDC, Asheville, North Carolina.

Wolyn, P. G. and T. B. McKee, 1987: Deep Stable Layers in the Intermountain Western United States. Mon. Wea. Rev., 117, 461-472.

Whiteman, C. D. and T. B. McKee, 1982: Breakup of Temperature Inversions in Deep Mountain Valleys: Part II. Thermodynamic Model. J. Appl. Met., $21,290-302$.

Whiteman, C. D., 1992: Wintertime Meteorology of the Grand Canyon Region. Six Conference on Mountain Meteorology. 29 Sept - 02 Oct 1992, 144-150. 